\title{
Effects of land-use changes on climate in southern South America
}

\author{
Natalia L. Pessacg ${ }^{1, *}$, Silvina Solman ${ }^{2}$ \\ ${ }^{1}$ Centro Nacional Patagónico (CENPAT/CONICET), Puerto Madryn, Chubut U9120ACF, Argentina \\ ${ }^{2}$ Centro de Investigaciones del Mar y la Atmósfera (CIMA/CONICET-UBA), DCAO/FCEN, UMI IFAECI/CNRS, \\ Buenos Aires C1428EGA, Argentina
}

\begin{abstract}
In the last decades, the agricultural areas over La Plata Basin and the Argentinean Pampas have been extended deforestation. With the aim of understanding the potential impacts of land-use changes over the South American climate, several simulations with the regional climate model MM5 were carried out for different idealized land-use scenarios representing agricultural expansion, reforestation and desertification, respectively. Results show a significant warming and drying when forests were replaced by bare soils due to an increase in the net radiation budget and a reduction in the latent heat flux. However, the replacement of forests by crops resulted in a decrease in the net radiation budget at the surface, together with a decrease in the latent and sensible heat fluxes, leading to a significant cooling over central and eastern Argentina and drying over Bolivia and western Paraguay. Finally, the shift from the actual land cover to crops produced a cooling and wetting mainly over northern Argentina, Paraguay and part of Bolivia due to a decrease in the net radiation budget and sensible heat flux and an increase in the latent heat flux. The regional response for these idealized scenarios exceeds the area where the land-use was changed, indicating that non-local mechanisms are important. A reduction in the roughness length when forest is replaced by either crops or bare soil leads to an increase in the northerly winds, which modifies the moisture flux convergence patterns and hence affects precipitation.
\end{abstract}

KEY WORDS: Land use/land cover - Southern South America - Regional climate model • Feedbacks soil-atmosphere

\section{INTRODUCTION}

La Plata Basin (LPB) and the Argentinean Pampas are 2 of the most important agricultural regions in the world. These areas are among the largest watersheds on Earth and comprise very important biomes interconnected by waterways (Viglizzo \& Frank 2006). During the last 3 decades of the 20th century, the areas devoted to agricultural production have been extended through deforestation and replacement of natural pastures (Pielke et al. 2011). Moreover, several studies indicate that deforestation continues to be the dominant land-use trend in Latin America (Achard et al. 2002). The main deforestation driver of tropical and subtropical forest in South America is the expansion of soy-bean cultivation, (Fearnside 2001, Kaimowitz \& Smith 2001, Baldi \& Paruelo 2008) which has been favoured by a positive interaction between increased rainfall over central and western Argentina together with new legislation and technology (Viglizzo et al. 1997).

Deforestation also drives other land use changes, such as the aridity/desertification process, which not only affects the landscape but also modifies the water cycle and the climate of the region. Over southern South America, almost three-quarters of the drylands have been moderately or severely affected by degradation processes and droughts (Magrin et al. 2007 
and references therein). In addition to this, a reforestation process has been taking place over LPB during the last decade, mainly over northeastern Argentina (Misiones, Entre Ríos and Corrientes provinces) and over Uruguay (FAO 2006), which includes forestation with natural species plus plantations with exotic trees, as well as invasion by these exotic trees over the grassland and shrubland (Zalba \& Villamil 2002).

Near-surface atmosphere variables such as precipitation and temperature are controlled not only by large scale atmospheric circulation, but also by the local interaction between the surface and the atmosphere (Barreiro \& Díaz 2011). The land properties, such as albedo, aerodynamic roughness and root depth vary among ecosystems and affect the land surface-atmosphere exchanges of heat, moisture and momentum, and control the partitioning of available water and energy at the surface. Consequently, land use/land cover changes (hereafter LULCC) may modify the exchanges of energy and moisture between the land surface and the atmosphere. Moreover, changes in vegetation composition can affect mesoscale atmospheric circulations (Weaver \& Avissar 2001), which in turn have significant effects on climate due to many positive and negative feedbacks, not only at the regional scale but also at the global scale (Strengers et al. 2010).

A limited number of studies that are focused on the impacts of LULCC on climate over southern South America can be found in the literature. Nuñez et al. (2008) suggested that positive temperature trends recorded during the last $30 \mathrm{yr}$ over the Argentinean Pampas could be associated with surface effects. Modelling studies (Blatter et al. 2010, Saulo et al. 2010) have shown that changes in land use have a marked effect on local climate, particularly on temperature and precipitation, but also on the regional circulation patterns. Beltrán-Przekurat et al. (2011) found that a shift from grass to agriculture led to cooler and wetter near-surface atmospheric conditions, and warmer conditions resulted from the conversion of wooded grasslands or forest to agriculture. Lee \& Berbery (2011) used an idealized scenario of land use change and showed that the LPB presents different climate responses to land cover changes, depending on the region. The northern part of the basin, where forests and savanna were replaced by crops, experienced a cooling and drying, while in the southern part of the basin, changes from grasslands to crops resulted in wetter and warmer conditions. Overall, the results and conclusions drawn by these studies are diverse, with some of them suggesting that the expansion of agricultural practices over south-eastern South America leads to a warming (wetting) effect, while others suggest a cooling (drying) effect. This diversity in the results is mainly related to the differences in the land use scenario imposed, and with the different methodologies used to assess the impact on the regional climate.

The goal of this study is to evaluate how LULCC may affect the regional climate, particularly on precipitation and temperature over LPB and the Argentinean Pampas at a seasonal timescale. With this aim, ensembles of sensitivity experiments for different idealized land use scenarios representing agricultural expansion, reforestation and desertification were performed using the Fifth-generation PennsylvaniaState University-NCAR nonhydrostatic Mesoscale Model (MM5). These scenarios represent potential practices over southern South America; consequently, understanding their possible effect on regional climate is also important in terms of ecosystem climate regulation services (West et al. 2011 and references therein).

\section{METHODOLOGY}

\subsection{Model description}

The MM5 model version 3.7 was used in this study. The integration domain covers from 10 to $45^{\circ} \mathrm{S}$ and from 85 to $35^{\circ} \mathrm{W}$ with 155 points in the west-east direction and 190 points in the south-north direction. It was configured on a Mercator projection grid with a resolution of $\sim 30 \mathrm{~km}$. In the vertical, 23 sigma levels were used with the model top at $50 \mathrm{hPa}$. The land-sea mask and topography have been derived from the US Navy 10 min resolution dataset. Vegetation and soil properties were obtained from the US Geological Survey (USGS) vegetation/land use data base, which prescribes 24 land cover types. Model domain and land use/land cover categories are shown in Fig. 1. The maps shown thereafter exclude the buffer zones.

All the simulations were performed using the set of physical schemes identified in Solman \& Pessacg (2012a) for which the model outperforms over South America. This set of schemes includes explicit moisture scheme by Hsie et al. (1984), a radiation scheme based on Stephens (1978) and Garand (1983), a convective scheme by Grell (1993), the planetary boundary layer parameterization formulated following Hong \& Pan (1996), and surface processes represented by the Noah Land Surface Model (Chen \& Dudhia 


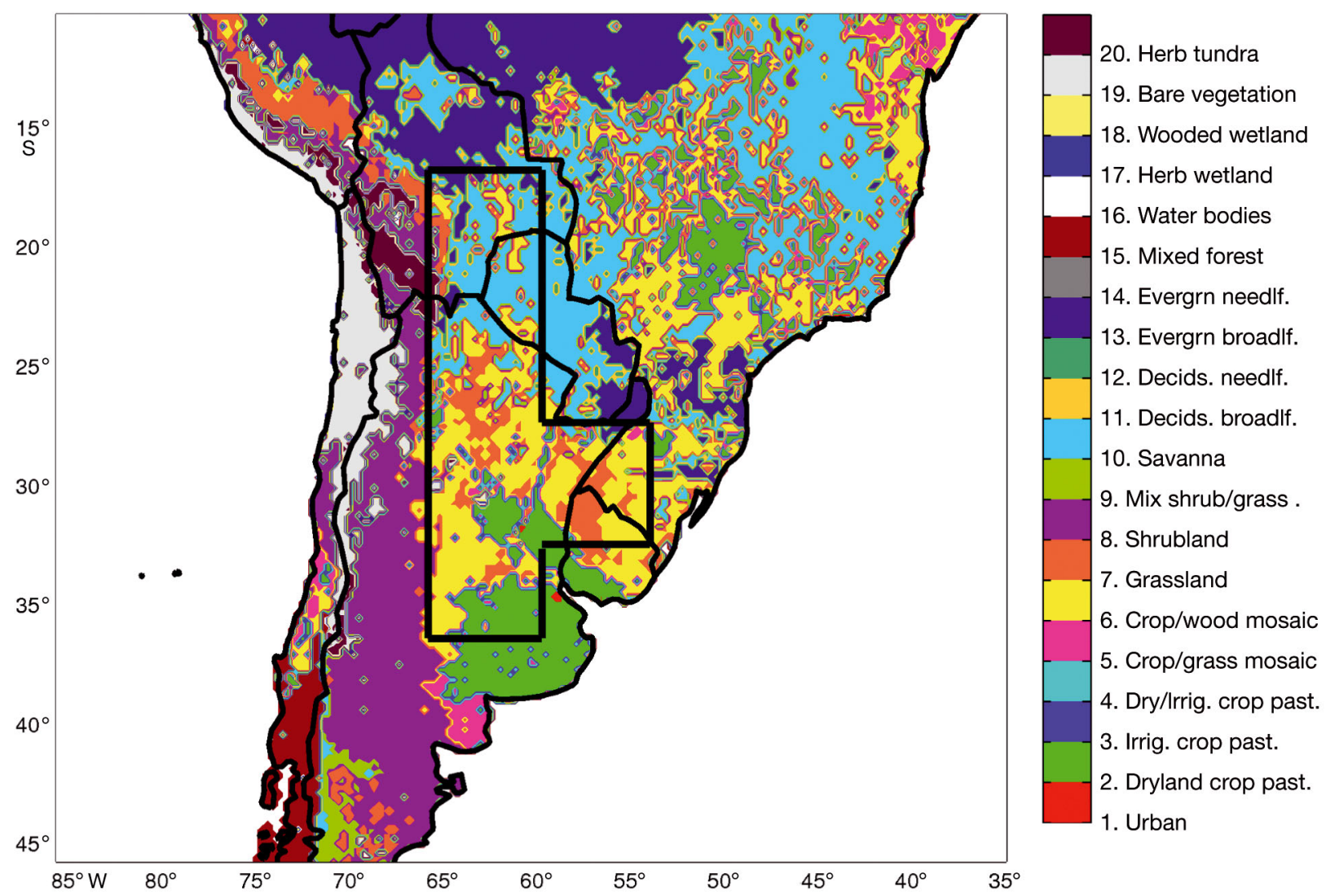

Fig. 1. Model domain and land use categories from USGS (shaded). Black box: region where land use was changed

2001). The land-surface model is capable of predicting soil moisture and temperature in 4 layers with thicknesses of 10, 30, 60 and $100 \mathrm{~cm}$, as well as canopy moisture and water-equivalent snow depth. The land surface model makes use of vegetation and soil type in handling evapotranspiration, and takes into account variations in soil conductivity and the gravitational flux of moisture.

\subsection{Experimental design}

Sensitivity experiments for different LULCC idealized scenarios were performed with the MM5 regional climate model (RCM) for the period March 1996March 1997, but only results for the austral spring season, September to November (SON), and the austral summer season, December to February (DJF), are analyzed here, allowing 6 mo for model spin-up. The period September 1996-March 1997 is not affected by El Niño Southern Oscillation (ENSO), which avoids including the influence of remote forcings on the regional climate features. In order to account for the internal variability in the assessment of the sig- nificance of the results, four-member ensembles for each LULCC scenario were performed by changing the starting date of the simulations from 1 to 4 March 1996. All the simulations last until 31 March 1997.

Initial and boundary conditions for the RCM were provided by the European Centre for Medium-range Weather and Forecasting reanalysis data set (ERAInterim) (Simmons et al. 2007) available at $1.5^{\circ} \times 1.5^{\circ}$ resolution. Boundary conditions were updated each 6 $\mathrm{h}$ and specified over a boundary relaxation zone covering the outermost 5 grid points at each side, with a relaxation constant that decreases linearly away from the outermost boundaries. Sea surface temperature was prescribed from ERA-Interim reanalysis. The land surface model coupled to the RCM also requires additional datasets for initial conditions over land, which include soil temperature and soil moisture at 4 layers below the surface $(0-7,7-28,28-100$ and $100-289 \mathrm{~cm}$ ) prescribed from the ERA-Interim reanalysis database.

Four sets of ensemble simulations were performed. For the control (CTRL) simulation, the land-use categories from the USGS database were used (Fig. 1), representing the actual land cover distribution. This 
simulation allows the evaluation of the RCM. The Climate Research Unit (CRU) data set was used for model validation.

An idealized scenario of LULCC assuming expansion of agriculture was designed in which the actual land cover over the LPB region and the Argentinean Pampas was replaced by dry land crop pasture (CROP experiment) within the area encompassed by the black box in Fig. 1. This idealized scenario of land use change over South America has been estimated from transformed maps based on satellite observations corresponding to 2000 and 2008 (www.proyungas.org.ar), together with land use changes reported in the LechuSA Project (http://lechusa.unsl.edu.ar) based on maps of differences in the normalized vegetation index and their relation with the land use changes.

The key physical properties (albedo, emissivity, roughness length and root zone depth) for the land use types within the target region are displayed in Table 1. Note that when crops replace the actual vegetation, changes in land cover types and in their physical properties are spatially heterogeneous. In particular, over the northern area replacement of savanna by crops implies decreasing the albedo and increasing the emissivity of the land-surface, while replacement of grassland and cropland/wooded mosaic by crops over central Argentina and southern Brazil implies patches of increasing or decreasing albedo and roughness length.

In addition, 2 extreme LULCC scenarios were defined in which the actual land cover was replaced by evergreen broadleaf forest (FOREST experiment) and by bare soils (BARE experiment) over the target region, representing reforestation and desertification scenarios, respectively. These idealized scenarios have 2 purposes. (1) They allow the quantification of upper bounds and the identification of the main drivers explaining changes in temperature and precipitation in response to extreme and homogeneous changes in land use or land cover. (2) They represent different LULCC potential practices over southern South America. A summary of the sensitivity experiments together with the key physical properties for the land use types used in this study are detailed in Table 1.

The FOREST ensemble will be compared first with the BARE ensemble with the aim of quantifying the impact of 2 extreme idealized scenarios representing reforestation and desertification, respectively, on the regional climate. Secondly, changes between CROP and FOREST ensembles will be discussed in order to
Table 1. Description of sensitivity experiments and key vegetation arameters used in this study. CTRL: main categories in black box of Fig. 1

\begin{tabular}{lcccc|}
$\begin{array}{l}\text { Experiment } \\
\text { Land use } \\
\text { categories (USGS) }\end{array}$ & $\begin{array}{c}\text { Surface } \\
\text { albedo } \\
(\%)\end{array}$ & $\begin{array}{c}\text { Emissivity } \\
(\% \text { at } 9 \mu \mathrm{m})\end{array}$ & $\begin{array}{c}\text { Roughness } \\
\text { length } \\
(\mathrm{cm})\end{array}$ & $\begin{array}{c}\text { Root } \\
\text { zone } \\
\text { layer }\end{array}$ \\
\hline CTRL & 20 & 92 & 15 & 3 \\
$\quad$ Savanna & 12 & 95 & 50 & 4 \\
$\quad \begin{array}{l}\text { Evergreen broadleaf } \\
\text { Dryland crop pasture }\end{array}$ & 17 & 98.5 & 15 & 3 \\
$\quad \begin{array}{l}\text { Cropland/Woodland } \\
\text { Grassland }\end{array}$ & 16 & 98.5 & 20 & 3 \\
$\begin{array}{l}\text { FOREST } \\
\text { Evergreen broadleaf }\end{array}$ & 12 & 98.5 & 12 & 3 \\
$\quad \begin{array}{l}\text { CROP } \\
\text { Dryland crop pasture }\end{array}$ & 17 & 98.5 & 50 & 4 \\
BARE & & & 15 & 3 \\
$\quad$ Bare sparse vegetation & 25 & 85 & 10 & 1 \\
\hline
\end{tabular}

explore the mechanisms and feedbacks that explain the differences associated with the hypothetical scenario in which crops are expanded at the expense of deforestation practices. Understanding these feedbacks will allow understanding the climate response when the actual land cover is replaced by crops (CROP versus CTRL).

\subsection{EVALUATION METHODS}

We assessed the significance of the climate response to the local forcings, comparing it with the internal variability, quantified as the square root of the time-averaged inter-member variance, as in Solman \& Pessacg (2012b). However, the magnitude of the internal variability may be biased due to the limited number of ensemble members used in this work (Alexandru et al. 2007). (2) Consequently, another measure of the robustness of the differences between 2 ensembles will be determined in terms of the number of individual pairs corresponding to each ensemble for which the difference is larger than a certain threshold. This metric, hereafter the NEM index, is quantified by means of:

$N E M[X(i, j)]_{\mathrm{e}_{1}, \mathrm{e}_{2}}=\sum_{\mathrm{k}=1}^{4} \sum_{\mathrm{l}=1}^{4}\left[\left(X_{\mathrm{e}_{1, \mathrm{k}}}(i, j)-X_{\mathrm{e}_{2,1}}(i, j)\right)>Y\right]$

where $X(i, j)$ is the variable at grid point $(i, j), \mathrm{e}_{1}$ and $\mathrm{e}_{2}$ represent 2 different ensembles, and $\mathrm{k}$ and 1 represent individual members of each ensemble. $Y$ is the threshold that is imposed as the condition for this index, being $Y=0.2^{\circ} \mathrm{C}$ for temperature and $Y=20 \%$ for precipitation. These limits correspond to upper bounds of the internal variability, which will be dis- 
cussed later. Note that the NEM for precipitation has been calculated based on normalized precipitation differences. Taking into account that each ensemble is built with 4 ensemble members, the maximum value that the NEM index can achieve is 16, indicating that for all possible pairs of combinations of 2 given ensembles, the magnitude of the difference is always larger than the threshold imposed. The NEM takes into account both positive and negative differences among ensemble members and is equal to the maximum number of pairs fulfilling the criteria. If the number of pairs for which the difference is negative is equal to the number of pairs for which the difference is positive, then NEM $=0$, indicating that no consistency is found among random pairs of different ensemble members.

\section{RESULTS}

\subsection{Model evaluation}

Fig. 2 shows the observed (CRU) and simulated (CTRL ensemble) precipitation and $2 \mathrm{~m}$ temperature $\left(T_{2 \mathrm{~m}}\right)$ for SON and DJF 1996-1997, respectively. The model reproduces adequately the precipitation pattern, though underestimates the maximum precipitation centre located over the LPB area during SON. It is worth mentioning that this is a common shortcoming of RCM simulations over South America (Menéndez et al. 2010, Solman \& Pessacg 2012a). Moreover, the model is able to reproduce wetter conditions during DJF and reproduces the band of maximum precipitation over the South Atlantic Convergence Zone extending within the Amazon basin, and the secondary precipitation maximum over north-eastern Argentina and southern Brazil. The precipitation increase from SON to DJF over most of the areas is mainly associated with the increase of moisture availability due to the increase of evaporation from the surface and/or the increase of moisture flux convergence.

Concerning temperature, the RCM simulates the observed mean $T_{2 \mathrm{~m}}$ during SON and DJF quite realistically over all the model domain except over central and northern Argentina and Paraguay, where a warm bias, mostly $<3^{\circ} \mathrm{C}$, is apparent. This result is consistent with the analysis presented by Solman et al. (2007) who attributed this warm bias to a dry bias in soil moisture content.

Fig. 3 shows the internal variability of the CTRL ensemble computed on the seasonal means. The internal variability for temperature is $\sim 0.1^{\circ} \mathrm{C}$ over most of the domain, with maximum values between $0.2^{\circ}$ and $0.3^{\circ} \mathrm{C}$ over north-eastern Argentina, Paraguay and south-eastern Brazil. For precipitation, the largest values of internal variability are found over tropical latitudes, ranging between 1 to $2 \mathrm{~mm} \mathrm{~d}^{-1}$, representing $\sim 18 \%$ of the total precipitation. Over northern Argentina and Uruguay, the internal variability is close to $10 \%$ of the total precipitation. For both temperature and precipitation the internal variability is slightly larger during DJF compared with SON. The rest of the ensembles showed a very similar behaviour for the internal variability pattern (not shown).

\subsection{Analysis of the idealized LULCC scenarios}

\subsubsection{FOREST and BARE scenarios}

Fig. 4 shows the difference between the BARE and FOREST ensembles for temperature and precipitation. Several sub-regions for further analysis are also displayed, hereafter NORTH, N-ARG, URU and EBRA, which are defined in terms of the response to LULCC.

A generalized temperature increase is simulated for the BARE experiment compared with FOREST, with the largest differences over NORTH and URU regions during $\mathrm{SON}$, up to $3^{\circ} \mathrm{C}$, and over the NORTH area during DJF with maximum values of $4^{\circ} \mathrm{C}$. The temperature change is extended out of the area where the land use was changed. The temperature change is significant in relation to both measures of significance: the 16 possible combinations of ensemble members (NEM index) captured the temperature change, and the magnitude of response is larger than the internal variability.

The differences for precipitation displayed in Fig. 4e,f show a decrease of precipitation in BARE over the NORTH region during both seasons, with the largest values during the DJF (ca. $-5 \mathrm{~mm} \mathrm{~d}^{-1}$ ). The physical signal is significant considering both the internal variability and the NEM index, which indicates that all of the possible ensemble members combinations are consistent.

Over the E-BRA region, which is located out of the region where the land use was changed, the BARE scenario induces consistent warm anomalies mainly during SON and displays an interesting behaviour for precipitation, with an opposite response during the 2 seasons, with a decrease (increase) of precipitation in BARE compared with FOREST during SON (DJF). In spite of the fact that the magnitude of the 


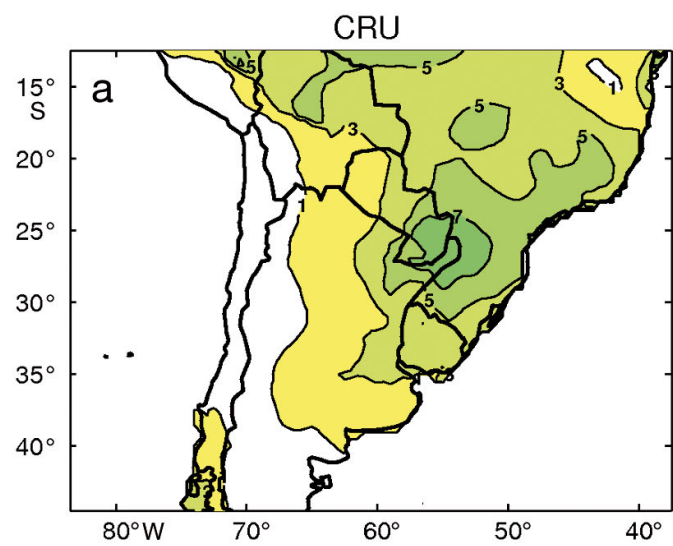

CTRL
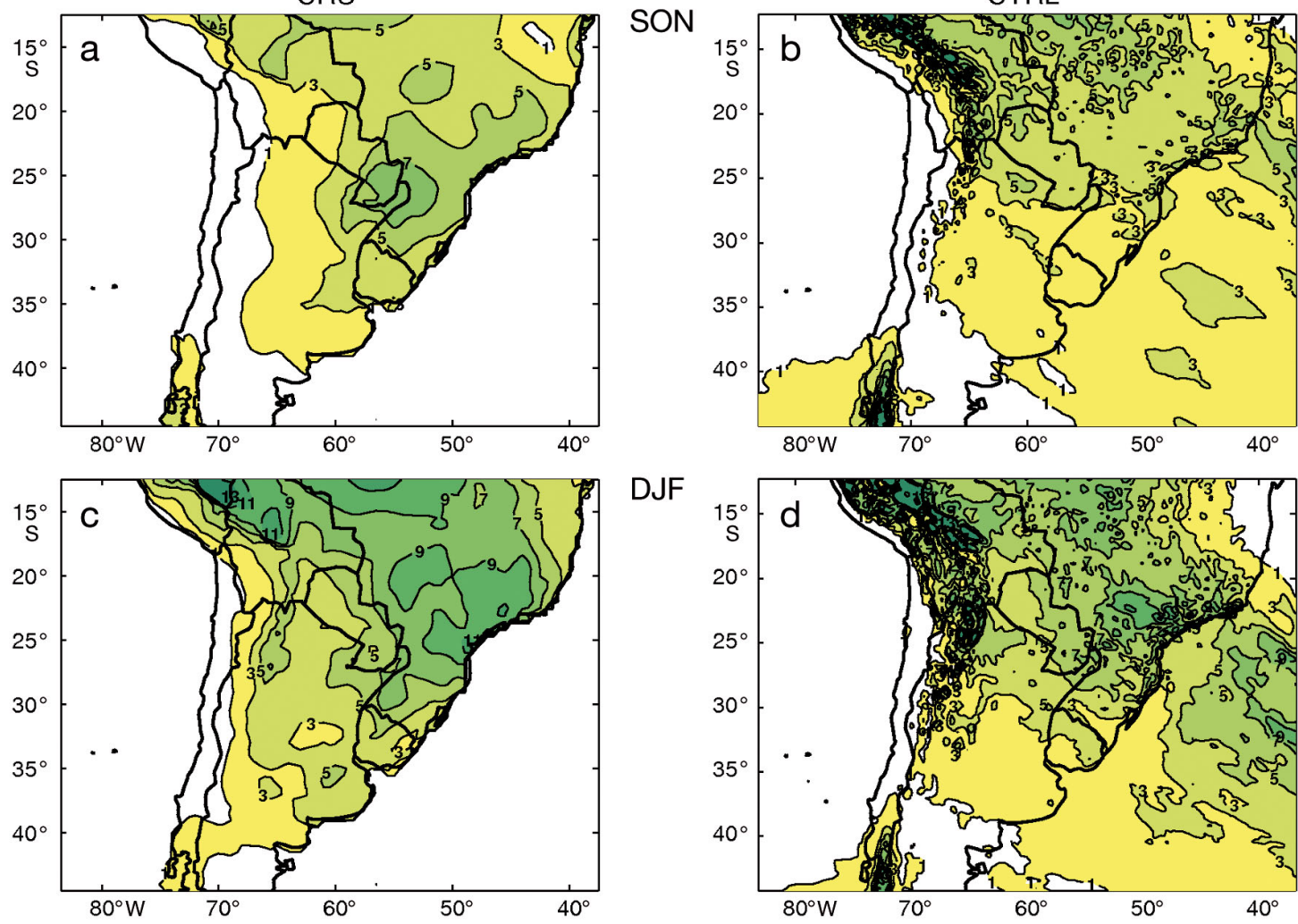

Precipi-

tation

$\left(\mathrm{mm} \mathrm{d}^{-1}\right)$

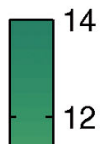

DJF
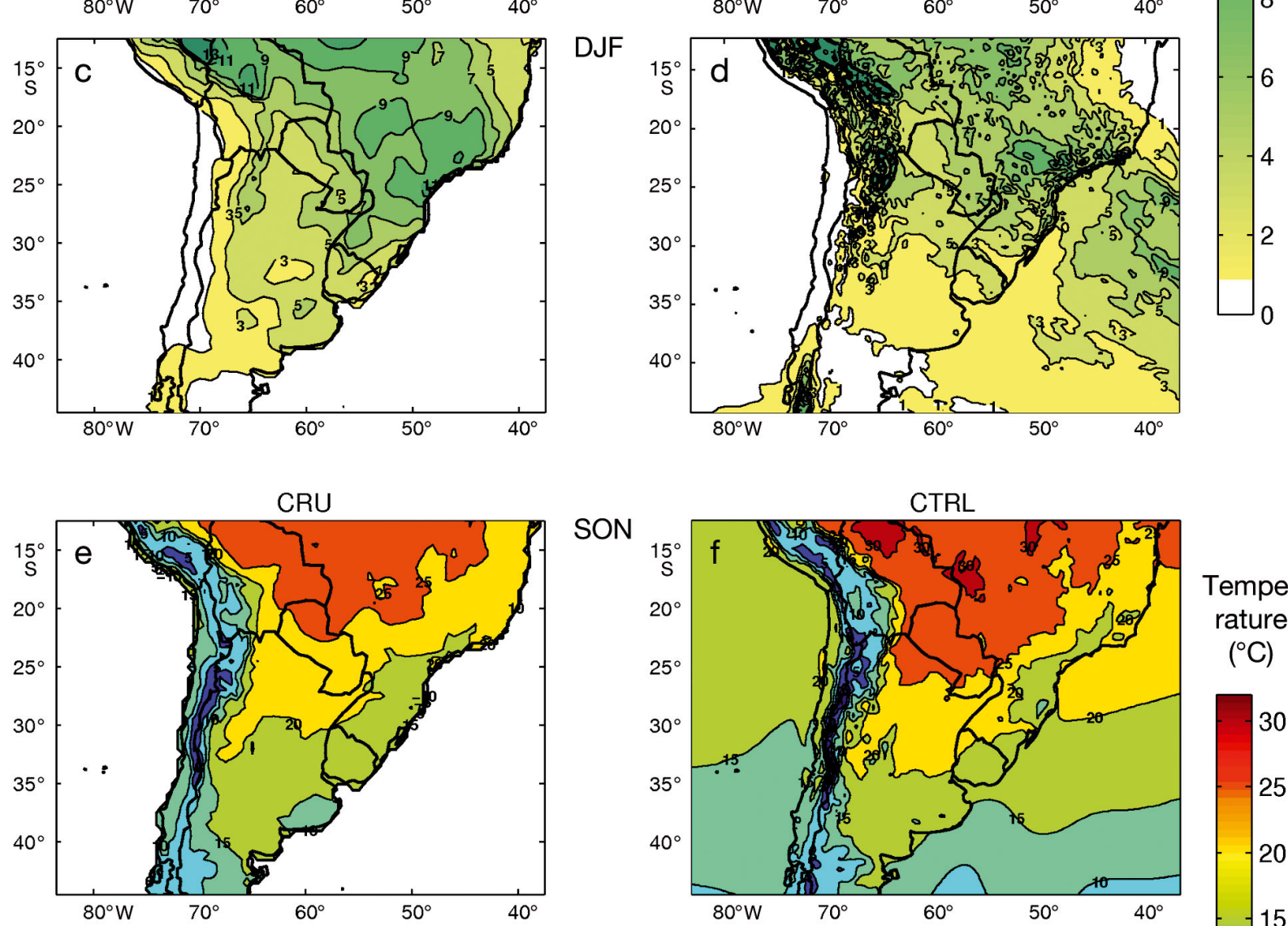

$\operatorname{son}$

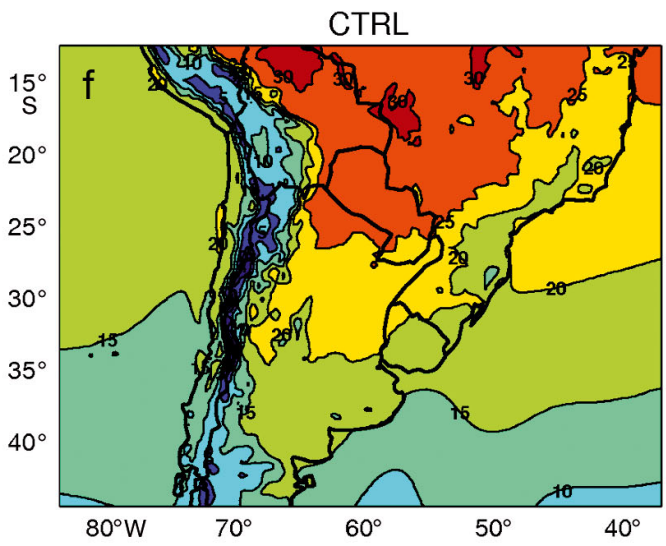

Temperature

$\left({ }^{\circ} \mathrm{C}\right)$

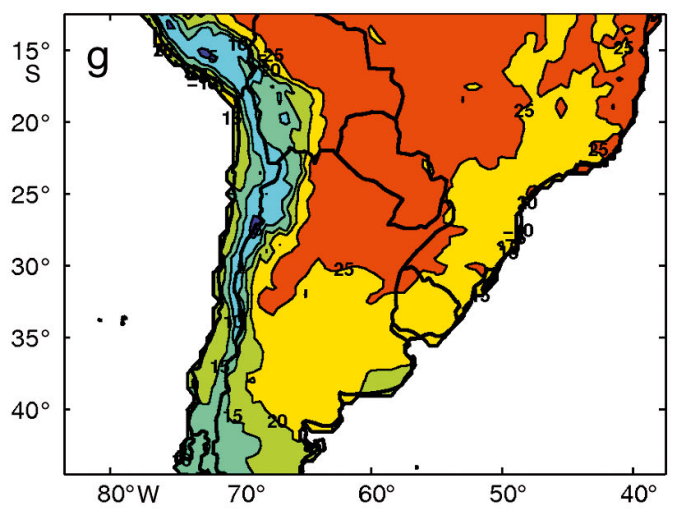

DJF
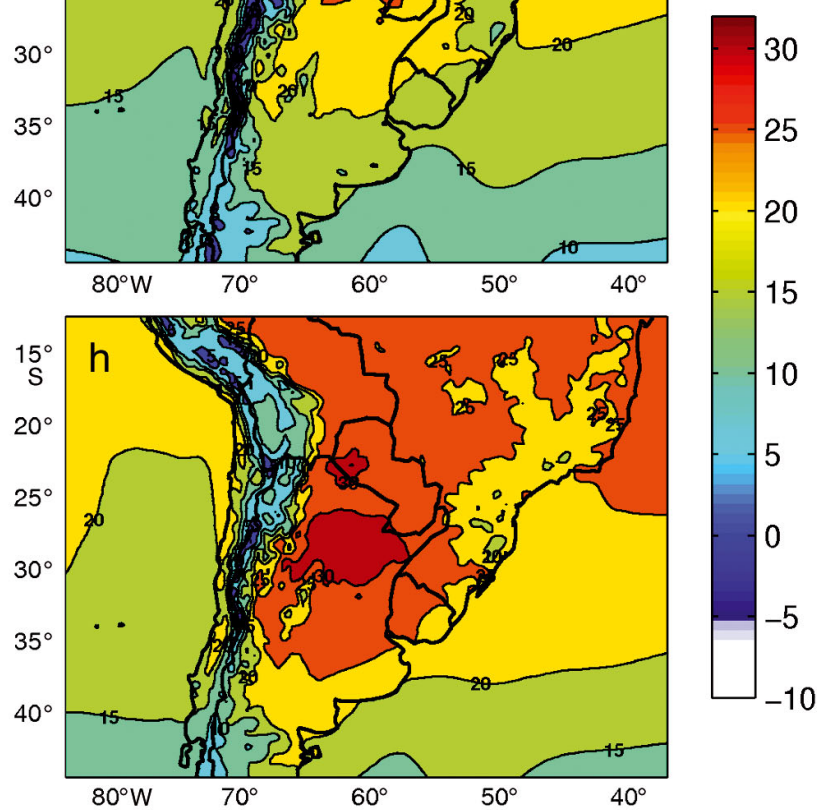

Fig. 2. CRU (left panels) and CTRL (right panels) experiment data for (a-d) precipitation (contours every $\left.2 \mathrm{~mm}^{-1}\right)$ and (e-h) temperature at $2 \mathrm{~m}\left(T_{2 \mathrm{~m}}\right.$ contours every $\left.5^{\circ} \mathrm{C}\right)$ during Sep-Nov (SON) and Dec-Feb (DJF) 

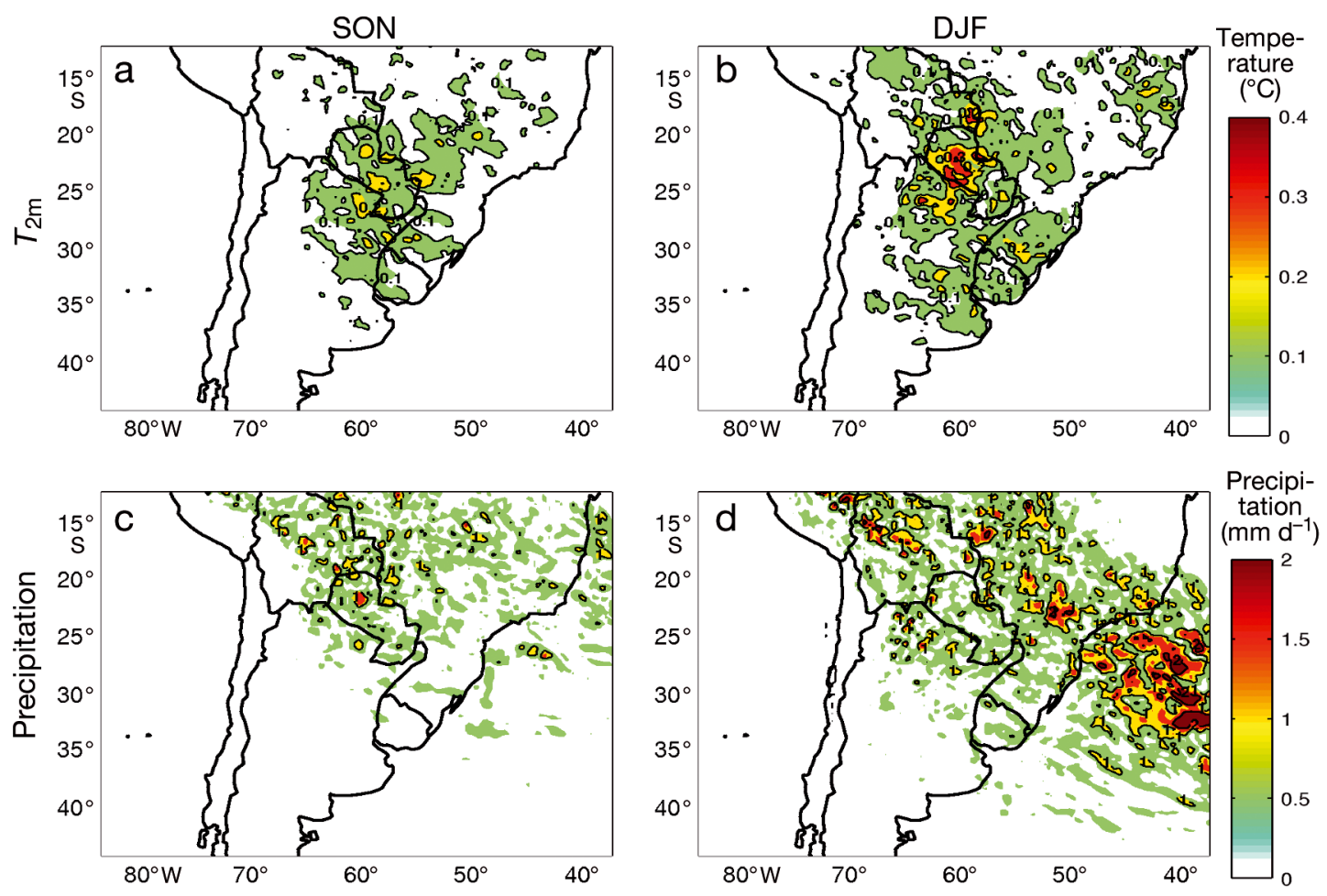

Fig. 3. Square root of the time-averaged inter-member variance for the CTRL ensemble for $(\mathrm{a}, \mathrm{b})$ temperature at $2 \mathrm{~m}\left(T_{2 \mathrm{~m}}\right)$ and $(\mathrm{c}, \mathrm{d})$ daily precipitation during Sep-Nov (SON) and Dec-Feb (DJF)

precipitation signal is within the magnitude of the internal variability, these anomalies are robust in terms of the NEM index.

Changes in near-surface temperature and precipitation induced by land cover changes are a consequence of changes in the moisture and energy budgets (Betts et al. 1996, Costa \& Pires 2010). With the aim of understanding the differences in temperature and precipitation related to LULCC, we evaluated the energy and water budgets over the regions of interest.

The main differences between the physical properties of the land surface when bare soils replace forests (Table 1) are a strong increase of the albedo and a reduction of the emissivity, roughness length and root depth. Fig. 5 summarizes the main processes contributing to the surface radiation budget averaged over the selected sub-regions identified in Fig. 4. Inspection of the long-wave and short-wave radiation components at the surface indicates that the changes in the downward components are less important in comparison to changes in the outward components (not shown). The increase of albedo leads to a decrease in the net shortwave radiation budget over NORTH, N-ARG and URU during both seasons, stronger in DJF than during SON. On the other hand, the reduction of emissivity reduces the net long wave radiation lost. The effects of albedo and emissivity have opposite contributions, leading to a decrease and an increase, respectively, in the net radiation budget. The net result over the N-ARG region is a weak decrease of the net radiation budget during DJF and a complete compensation during SON. Over URU and NORTH regions the emissivity effect is larger than the albedo effect and the net radiation budget is increased during both seasons.

For each ensemble averaged over each sub-region, Fig. 6 shows the latent and sensible heat fluxes and their ratio (Bowen ratio), and Table 2 shows a summary of the impact of land use changes on temperature, precipitation, evaporation, moisture flux convergence and cloud fraction. Over N-ARG, URU and NORTH regions, replacing forest by bare soils leads to a strong reduction of latent heat flux during both seasons. This may be related to the decrease in aerodynamic roughness induced by a decrease in the roughness length together with a decrease in root depth and decreased soil moisture at the upper soil layers (not shown). A decrease in the latent heat flux in BARE contributes to a decrease in evaporative cooling at the surface and hence to increased surface temperature. Changes in energy partition between latent and sensible heat fluxes lead to a marked increase in the Bowen ratio during both seasons, which becomes $>1$ in the BARE scenario, indicating that the 

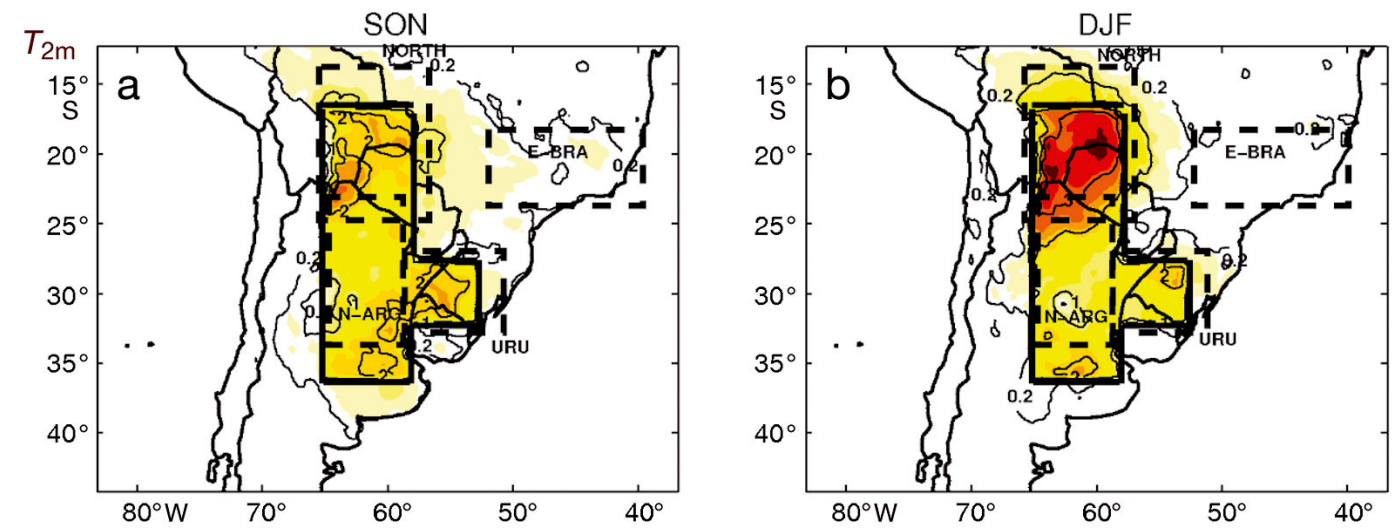

Tempera-

ture $\left({ }^{\circ} \mathrm{C}\right)$
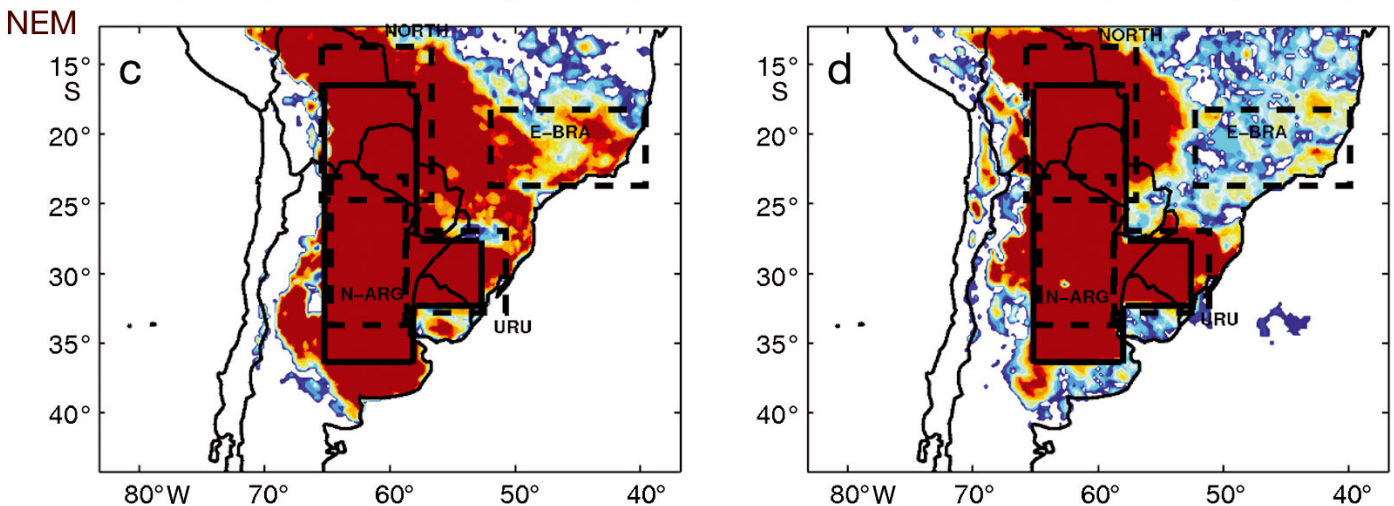

NEM temperature index
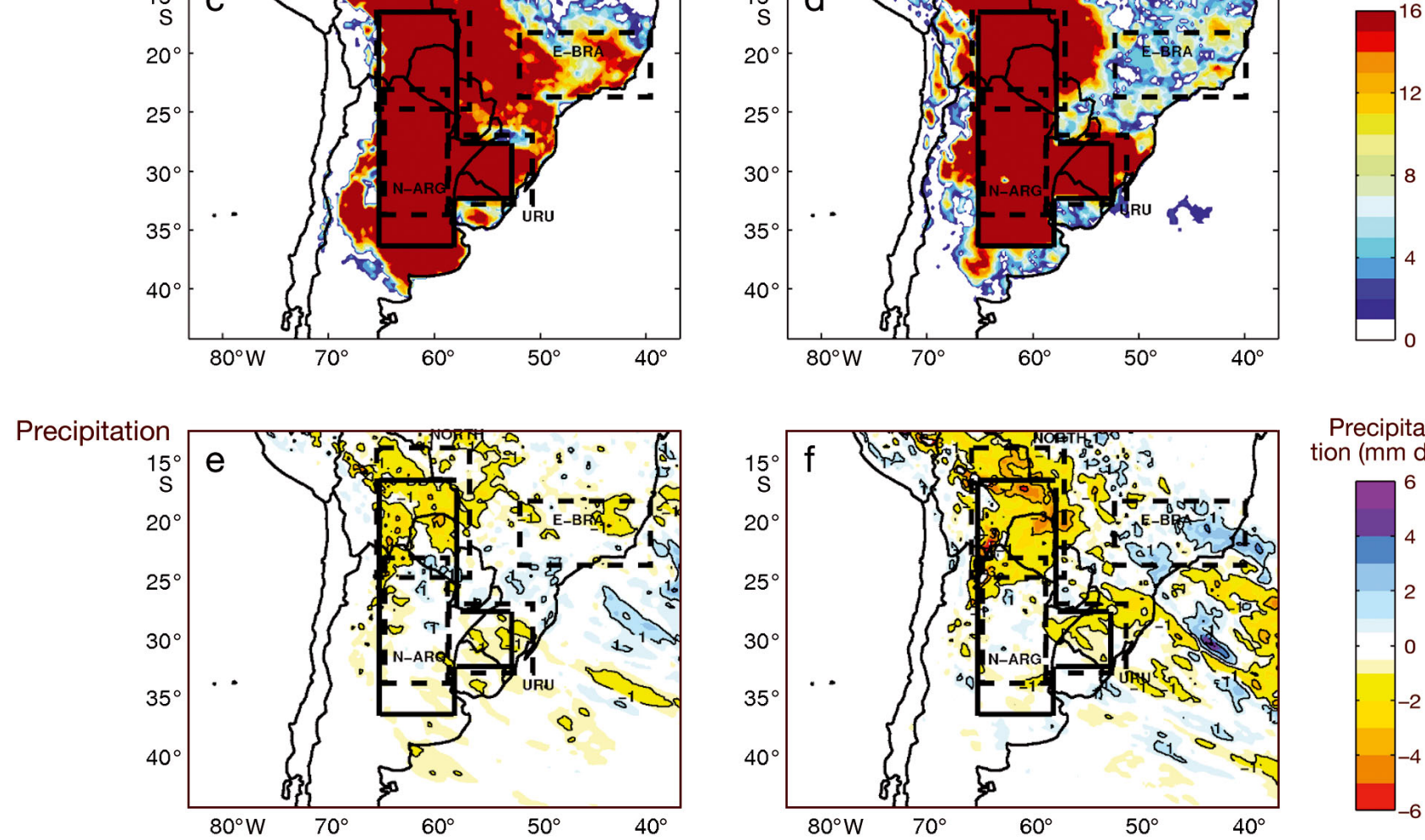

Precipitation $\left(\mathrm{mm} \mathrm{d}^{-1}\right)$
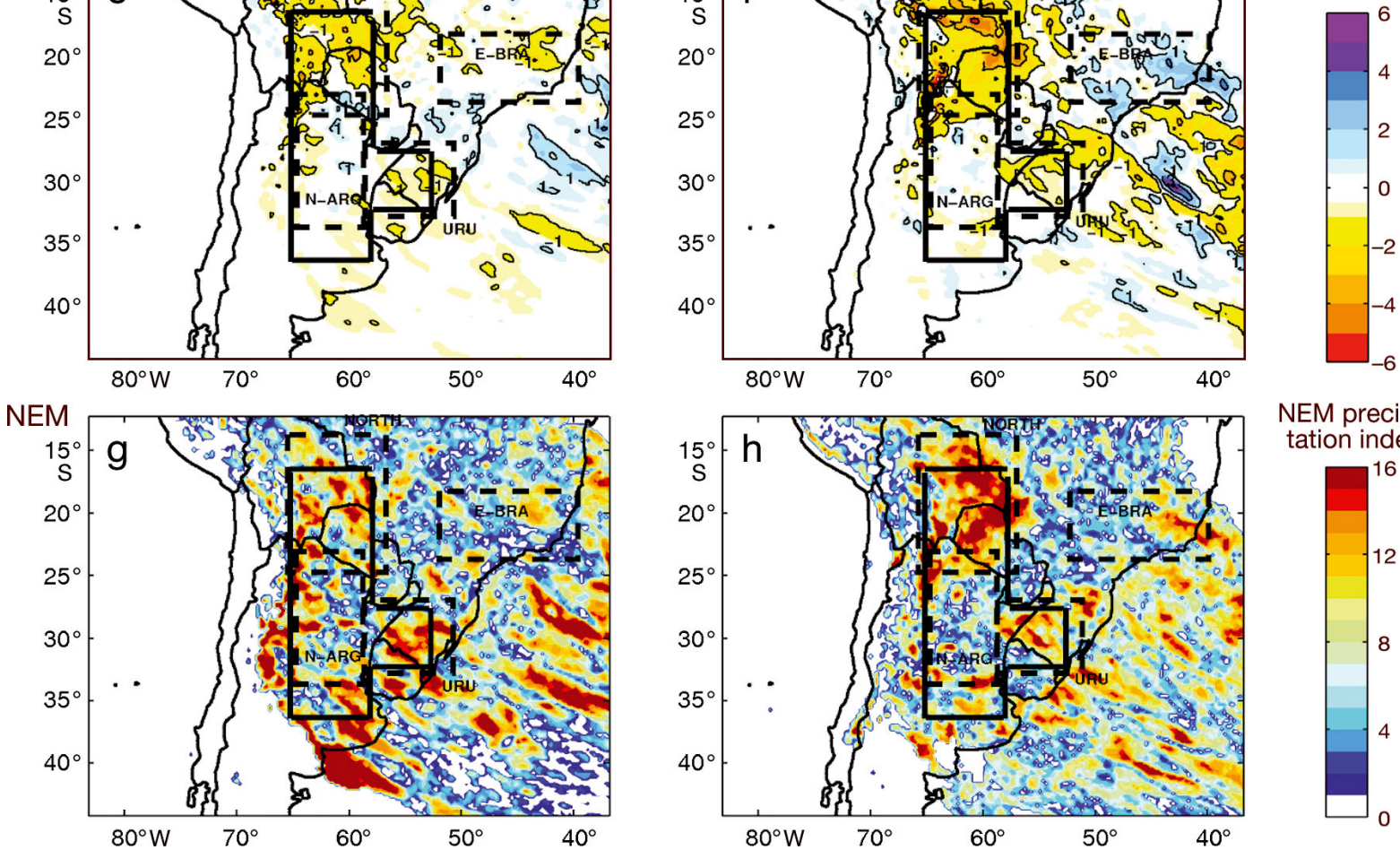

NEM precipitation index

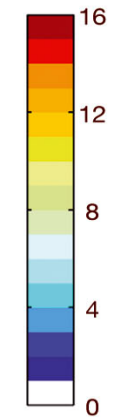

Fig. 4. Differences between BARE and FOREST ensembles in $(\mathrm{a}, \mathrm{b})$ temperature at $2 \mathrm{~m}\left(T_{2 \mathrm{~m}}\right),(\mathrm{c}, \mathrm{d})$ NEM index for temperature, $(\mathrm{e}, \mathrm{f})$ daily precipitation and $(\mathrm{g}, \mathrm{h}) \mathrm{NEM}$ index for precipitation during Sep-Nov (SON) and Dec-Feb (DJF), respectively. Solid box: region where land use was changed. Dashed box: sub-regions NORTH, N-ARG, URU and E-BRA 

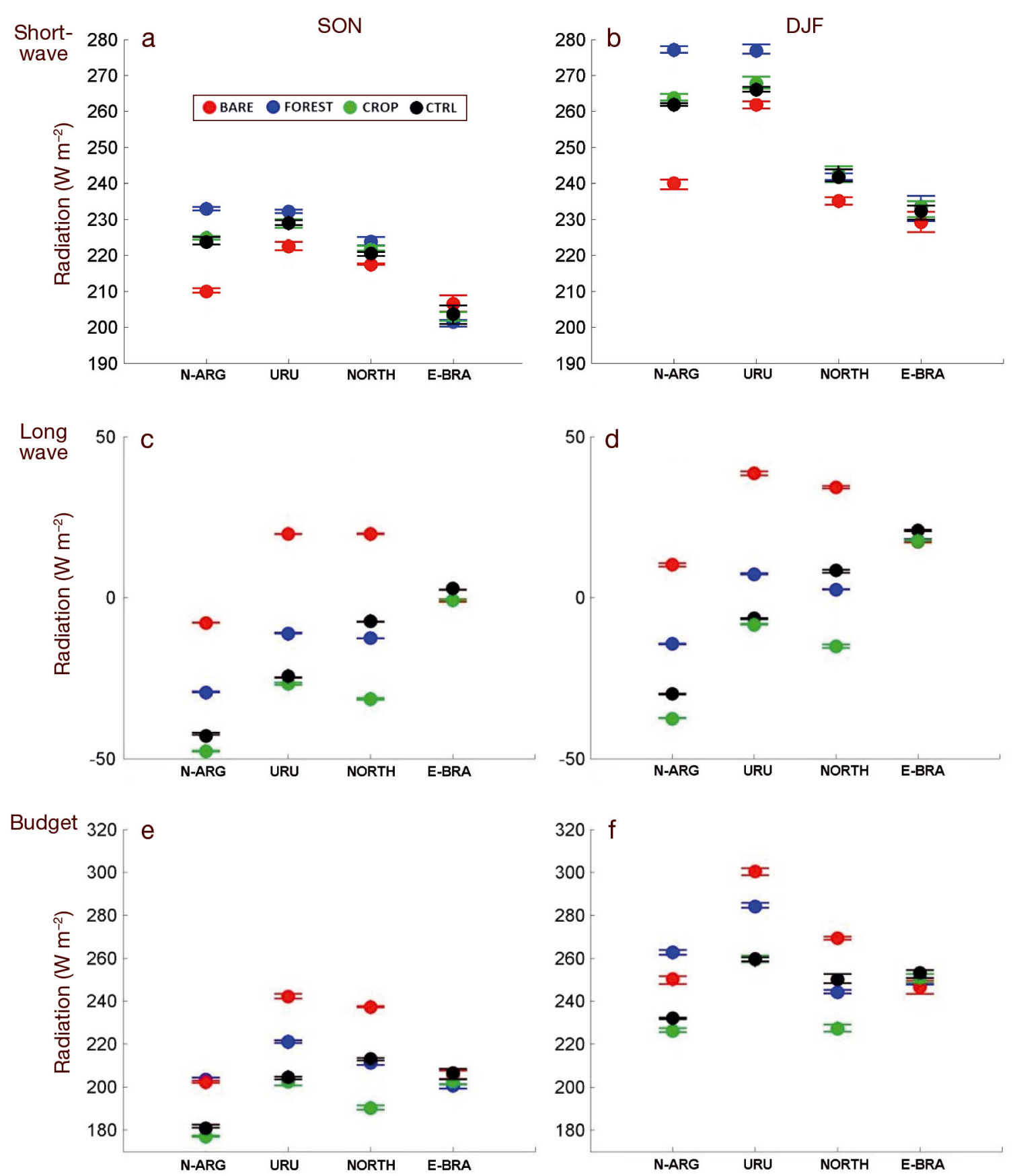

Fig. 5. Net $(a, b)$ short wave, $(c, d)$ long wave, and $(e, f)$ radiation budgets at surface during Sep-Nov (SON) and Dec-Feb (DJF), respectively. Circles: mean budgets for each experiment in each region described in Fig. 4. Bars: maximum and minimum values of budgets for ensembles members

sensible heat flux at the surface is larger than the latent heat flux. This mechanism is a channel for dissipating heat contributing to the warming.

As pointed out by Lee \& Berbery (2011), local and non-local effects, such as surface fluxes and moisture flux convergence, respectively, are both relevant to the atmospheric water balance. In order to account for the non-local effects, the vertically integrated moisture flux and moisture flux convergence for the FOREST ensemble and for the difference between BARE and FOREST are shown in Fig. 7. The FOREST ensemble shows a region of large convergence over NORTH, URU and E-BRA during both seasons. The idealized desertification scenario resulted in a reduction of the moisture flux convergence over the NORTH and URU regions (stronger during summer) 

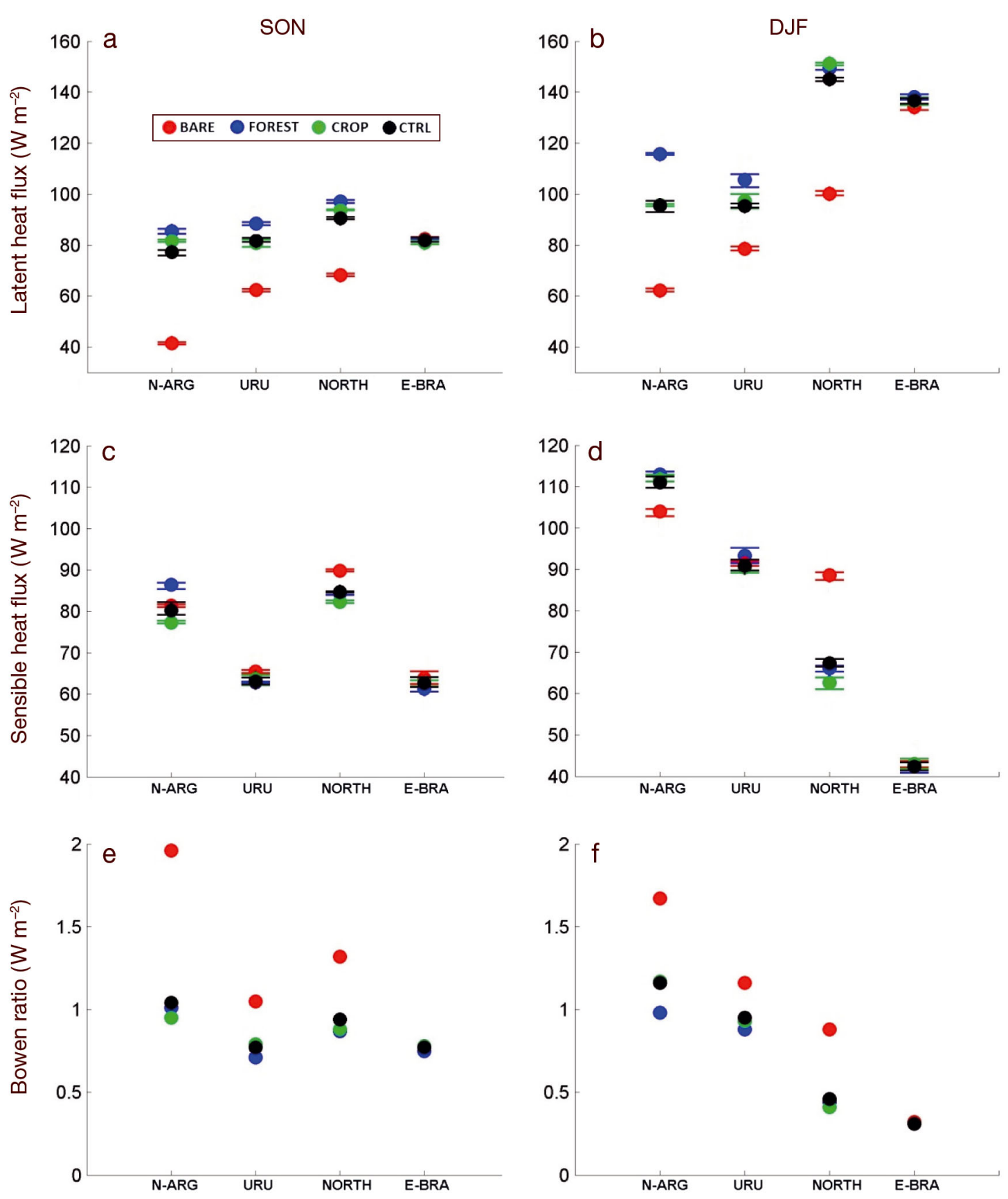

Fig. 6. $(\mathrm{a}, \mathrm{b})$ Latent and $(\mathrm{c}, \mathrm{d})$ sensible heat fluxes and $(\mathrm{e}, \mathrm{f})$ the Bowen ratio during Sep-Nov (SON) and Dec-Feb (DJF), respectively. See Fig. 5 for further details

associated with increased northerly winds due to the reduced roughness length in BARE (Table 1), contributing to drying conditions. This change in low level circulation is the response to the deepening of the thermal north-western Argentinean Low due to the warming and drying of the surface, in agreement with Saulo et al. (2010) and Blatter et al. (2010).

Over the E-BRA region, which is located out of the region where the land use was modified, though there are non-significant changes in the energy budget (Figs. $5 \& 6$ ), there is a decrease (increase) in the moisture flux convergence during SON (DJF), leading to a decrease (increase) in precipitation.

Summarizing, the main impact of the shift from a reforestation scenario to a desertification scenario is a generalized warming over the area where the land use was changed, as well as external to this region. The differences between both scenarios illustrate a 
Table 2. Mean data for $2 \mathrm{~m}$ temperature $\left(T_{2 \mathrm{~m}}\right)$, daily precipitation, evaporation, vertically integrated moisture flux convergence, and cloud fraction at low levels during Sep-Nov (SON) and Dec-Feb (DJF) 1996-1997 over the N-ARG, URU, NORTH and E-BRA regions for each experiment (FOREST, BARE, CROP and CTRL)

\begin{tabular}{|c|c|c|c|c|c|c|c|c|}
\hline & \multicolumn{2}{|c|}{ N-ARG } & \multicolumn{2}{|c|}{ URU } & \multicolumn{2}{|c|}{ NORTH } & \multicolumn{2}{|c|}{ E-BRA } \\
\hline & SON & DJF & $\mathrm{SON}$ & DJF & SON & DJF & SON & DJF \\
\hline \multicolumn{9}{|l|}{$T_{2 m}\left({ }^{\circ} \mathrm{C}\right)$} \\
\hline FOREST & 23.39 & 29.39 & 19.60 & 25.70 & 25.37 & 26.19 & 22.50 & 24.10 \\
\hline BARE & 24.89 & 30.92 & 20.56 & 26.46 & 26.66 & 28.26 & 22.78 & 24.03 \\
\hline CROP & 22.96 & 29.36 & 19.62 & 25.56 & 25.36 & 26.25 & 22.60 & 24.12 \\
\hline CTRL & 23.12 & 29.45 & 19.60 & 25.65 & 25.50 & 26.49 & 22.57 & 24.09 \\
\hline \multicolumn{9}{|c|}{ Precipitation $\left(\mathrm{mm} \mathrm{d}^{-1}\right)$} \\
\hline FOREST & 2.83 & 3.94 & 2.32 & 3.09 & 5.43 & 7.28 & 4.28 & 6.49 \\
\hline BARE & 2.64 & 3.49 & 1.81 & 2.66 & 4.47 & 5.16 & 4.04 & 7.09 \\
\hline CROP & 2.90 & 3.69 & 2.02 & 3.24 & 5.01 & 6.40 & 4.24 & 6.56 \\
\hline CTRL & 2.76 & 3.73 & 2.03 & 3.27 & 4.94 & 6.17 & 4.26 & 6.74 \\
\hline \multicolumn{9}{|c|}{ Evaporation (mm d $\left.\mathbf{d}^{-1}\right)$} \\
\hline FOREST & 3.01 & 4.08 & 3.12 & 3.72 & 3.42 & 5.27 & 2.89 & 4.87 \\
\hline BARE & 1.46 & 2.19 & 2.20 & 2.77 & 2.41 & 3.53 & 2.90 & 4.73 \\
\hline CROP & 2.88 & 3.37 & 2.85 & 3.43 & 3.30 & 5.33 & 2.86 & 4.81 \\
\hline CTRL & 2.72 & 3.37 & 2.88 & 3.36 & 3.19 & 5.12 & 2.89 & 4.83 \\
\hline \multicolumn{9}{|c|}{ Moisture convergence $\left(\mathrm{mm} \mathrm{d}^{-1}\right)$} \\
\hline FOREST & 0.60 & 0.43 & -1.14 & -1.43 & -0.85 & -2.47 & -2.72 & -4.85 \\
\hline BARE & -0.88 & 0.88 & -1.31 & 0.00 & -0.88 & -0.42 & -2.51 & -5.21 \\
\hline CROP & 0.19 & 1.51 & -0.95 & -0.51 & -0.70 & -1.08 & -2.70 & -4.60 \\
\hline CTRL & 0.27 & 1.31 & -1.04 & -0.49 & -0.68 & -0.87 & -2.68 & -4.79 \\
\hline \multicolumn{9}{|c|}{ Low cloud fraction } \\
\hline FOREST & 0.38 & 0.42 & 0.44 & 0.47 & 0.49 & 0.64 & 0.58 & 0.68 \\
\hline BARE & 0.25 & 0.29 & 0.39 & 0.41 & 0.36 & 0.44 & 0.57 & 0.68 \\
\hline CROP & 0.35 & 0.39 & 0.42 & 0.49 & 0.47 & 0.62 & 0.58 & 0.68 \\
\hline CTRL & 0.338 & 0.387 & 0.426 & 0.485 & 0.455 & 0.596 & 0.582 & 0.685 \\
\hline
\end{tabular}

significant drying that intensifies from SON to DJF, mainly over the NORTH area. Over the E-BRA area there is an exception to this behaviour, and opposite precipitation anomalies are found during the 2 seasons analyzed.

These changes are mostly controlled by changes in the net radiation budget. The warming can be explained due to the increase in the net radiation budget together with the strong reduction in the latent heat flux and the increase in the Bowen ratio. Additionally, the soil storage in BARE also increases (not shown). On the other hand, the reduced availability of moisture near the surface in the desertification scenario due to a decrease in evaporation from the surface, together with a relatively more stable planetary boundary layer (not shown), may explain the decrease in low and medium-level cloud cover fraction and a decrease in precipitation. Note that the decrease (increase) in the latent (sensible) heat flux is larger during DJF compared with SON, particularly over NORTH. The reduced precipitation over NORTH during SON impacts the soil moisture (not shown) drying the soils, which enhances the drying during the DJF season.

Non-local effects, such as changes in the moisture flux convergence, play an additional role not only over the regions directly affected by changes in land-use cover.

\subsubsection{FOREST and CROP scenarios}

The differences in the seasonal mean temperature and precipitation between the CROP and FOREST ensembles during SON and DJF are displayed in Fig. 8. The more interesting features when crops replace forests are the cooling over N-ARG during SON reaching values close to $1{ }^{\circ} \mathrm{C}$, over URU during DJF, and the warming over NORTH that intensifies from spring to summer. The magnitude of the temperature response is significant in terms of the 2 criteria used in this work: it is larger than the internal variability, and the NEM index suggests consistency among ensemble members. This result agrees with other studies such as Oleson et al. (2004) and Bonan (1999), who showed a surface annual mean cooling of 0.6 to $1^{\circ} \mathrm{C}$ (larger during summer) over central and eastern USA as a result of deforestation and replacement by crops.

For precipitation, the largest differences between the CROP and FOREST ensembles are located over the NORTH region, showing a drying during SON that intensifies during DJF. Though the magnitude of the response in precipitation is close to the magnitude of the internal variability, it is significant in terms of the NEM index for both seasons. It is also important to highlight the wet anomaly over the E-BRA region during DJF, in agreement with the response found between the BARE and FOREST ensembles.

The differences between CROP and FOREST showed an opposite response in temperature over N-ARG and URU regions, compared with the differences between BARE and FOREST. The response in precipitation has a similar pattern when forests are replaced by either crops or bare soils, though the amplitude of the difference is weaker in the former. 


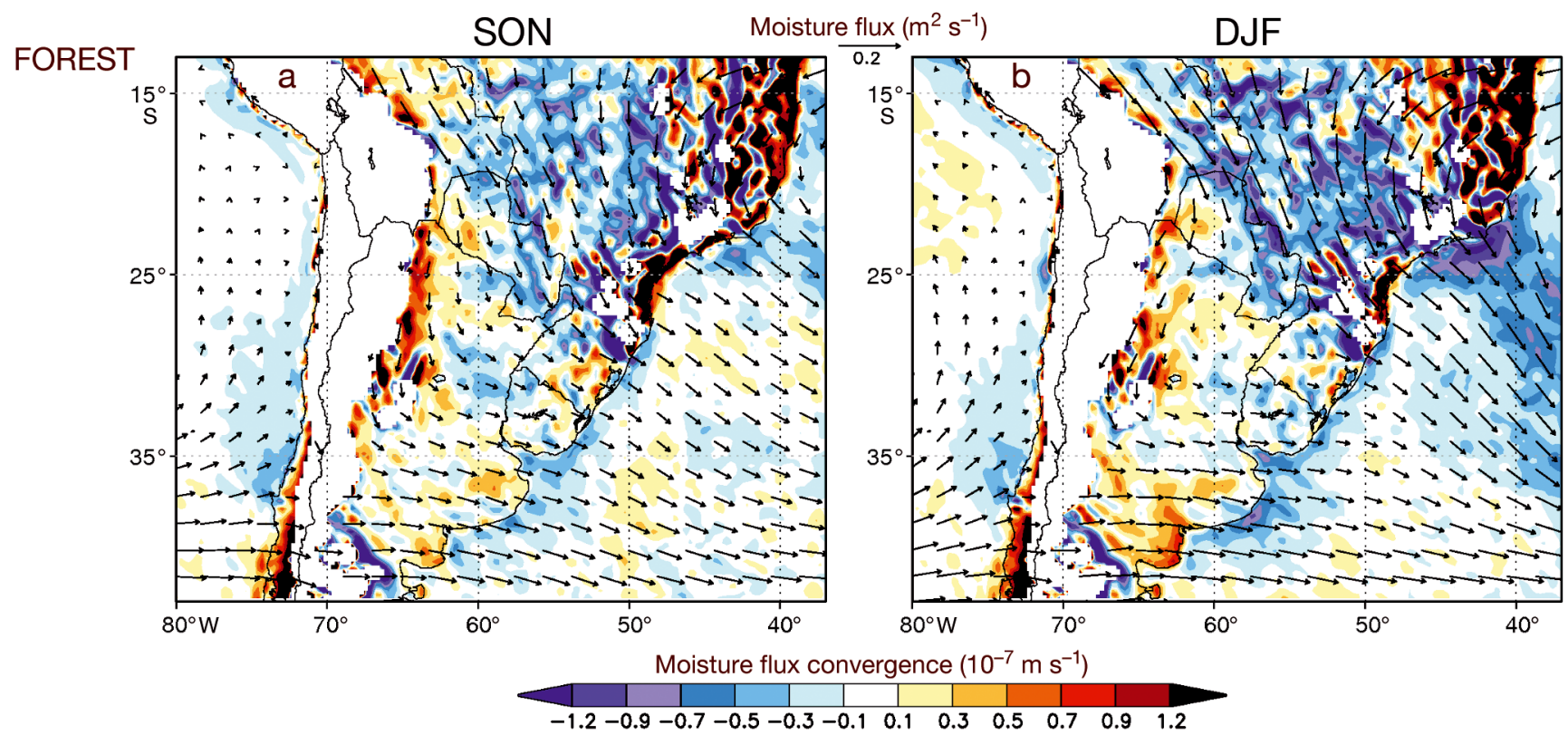

BAREFOREST

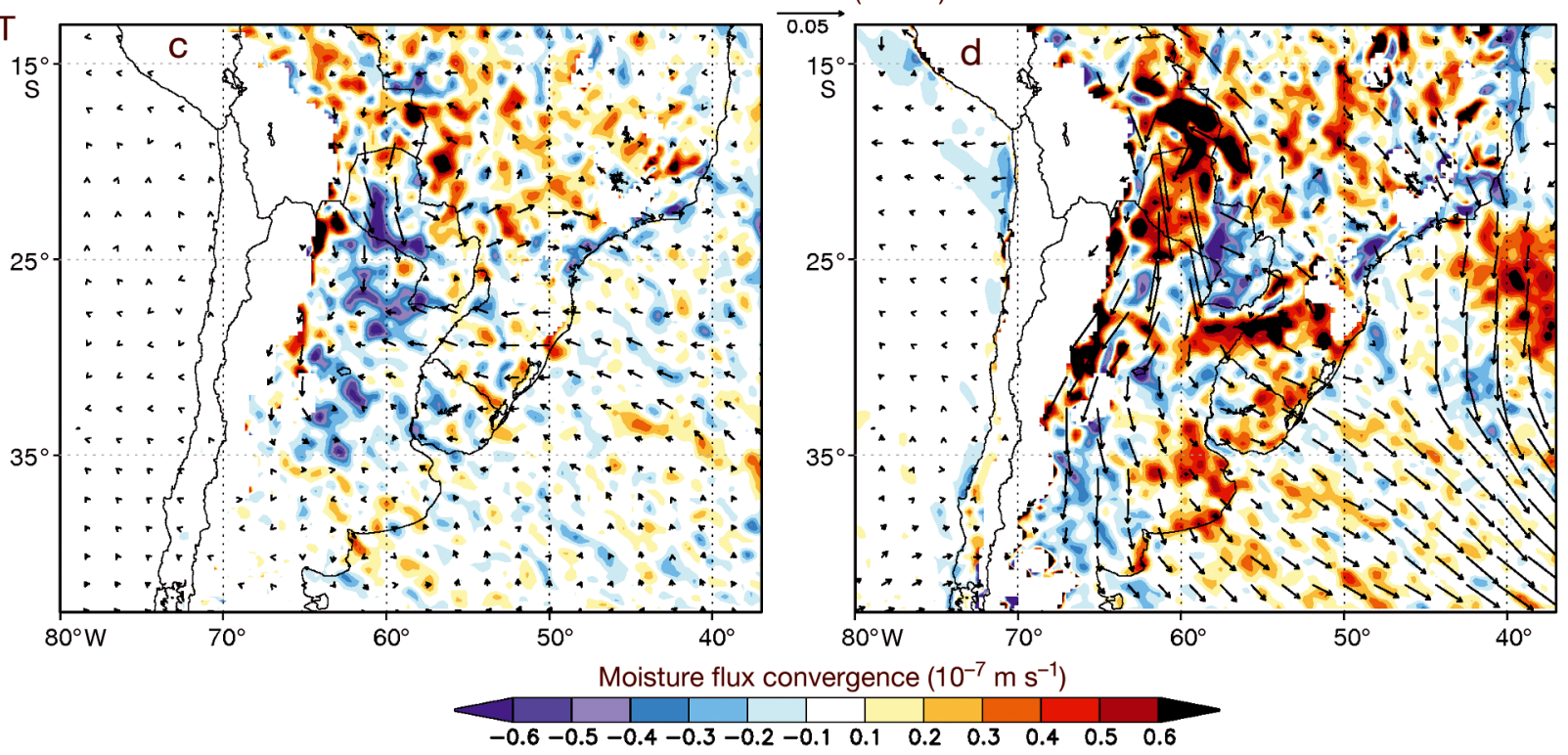

Fig. 7. Moisture flux (vectors) and moisture flux convergence vertically integrated from 925 to 500 hPa (color) for (a,b) FOREST and $(\mathrm{c}, \mathrm{d})$ the difference between BARE and FOREST experiments during Sep-Nov (SON) and Dec-Feb (DJF), respectively

The main differences in the physical properties between the CROP and FOREST scenarios are the increase of albedo and emissivity and the decrease in roughness length and root depth, as shown in Table 1. The differences in physical properties between these land-use categories are smaller than in the previous case in which FOREST and BARE scenarios were compared; consequently, the changes in the surface energy balance are also expected to be smaller. The increased albedo and emissivity lead to a decrease in the net radiation budget during both seasons over the areas affected by the land-use change (Fig. 5). In this case, both the albedo and the emissivity effects induce the same response in the net radiation budget. The decreased roughness length and root depth induce a reduction of both sensible and latent heat fluxes (Fig. 6), though these differences are subtle over most of the regions. The net cooling over the N-ARG region during SON when crops replace forests are probably due mainly to the reduction of available energy at the surface and a reduction of the sensible heat flux, which drops $\sim 13 \%$.

The precipitation decrease identified in Fig. 8e,f over the NORTH region can be principally explained 

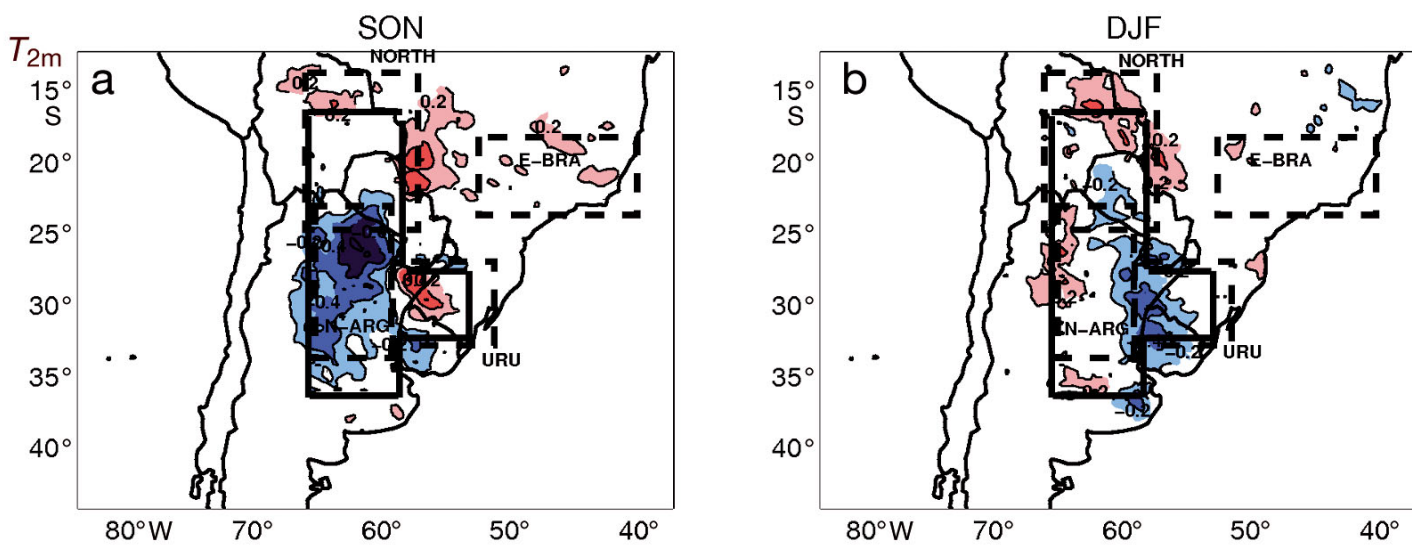

Tempera-

ture $\left({ }^{\circ} \mathrm{C}\right)$
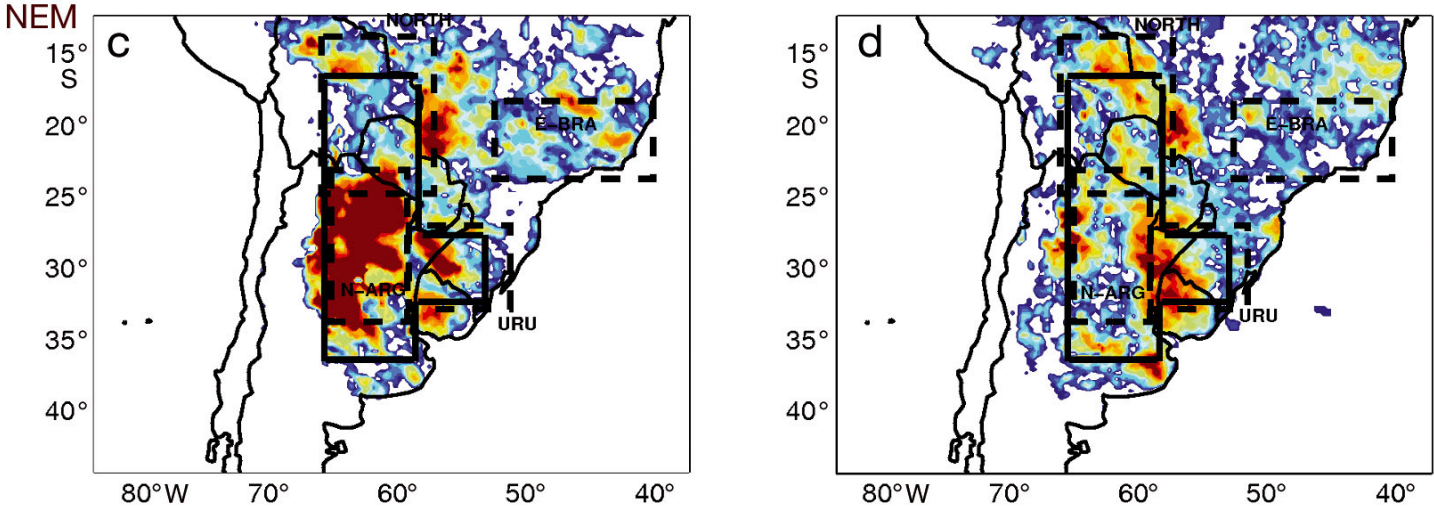

NEM temperature index
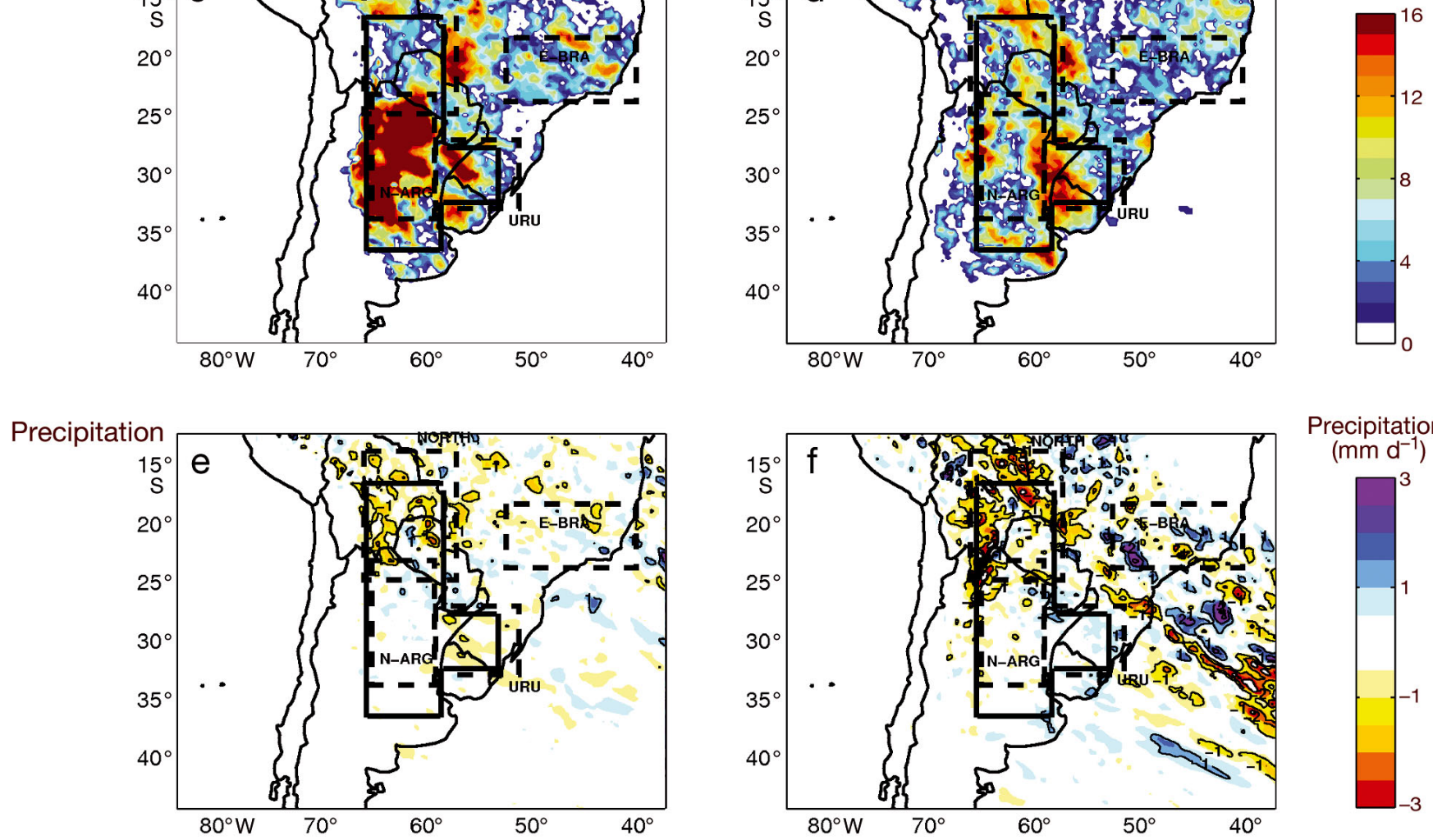

Precipitation $\left(\mathrm{mm} \mathrm{d}^{-1}\right)$
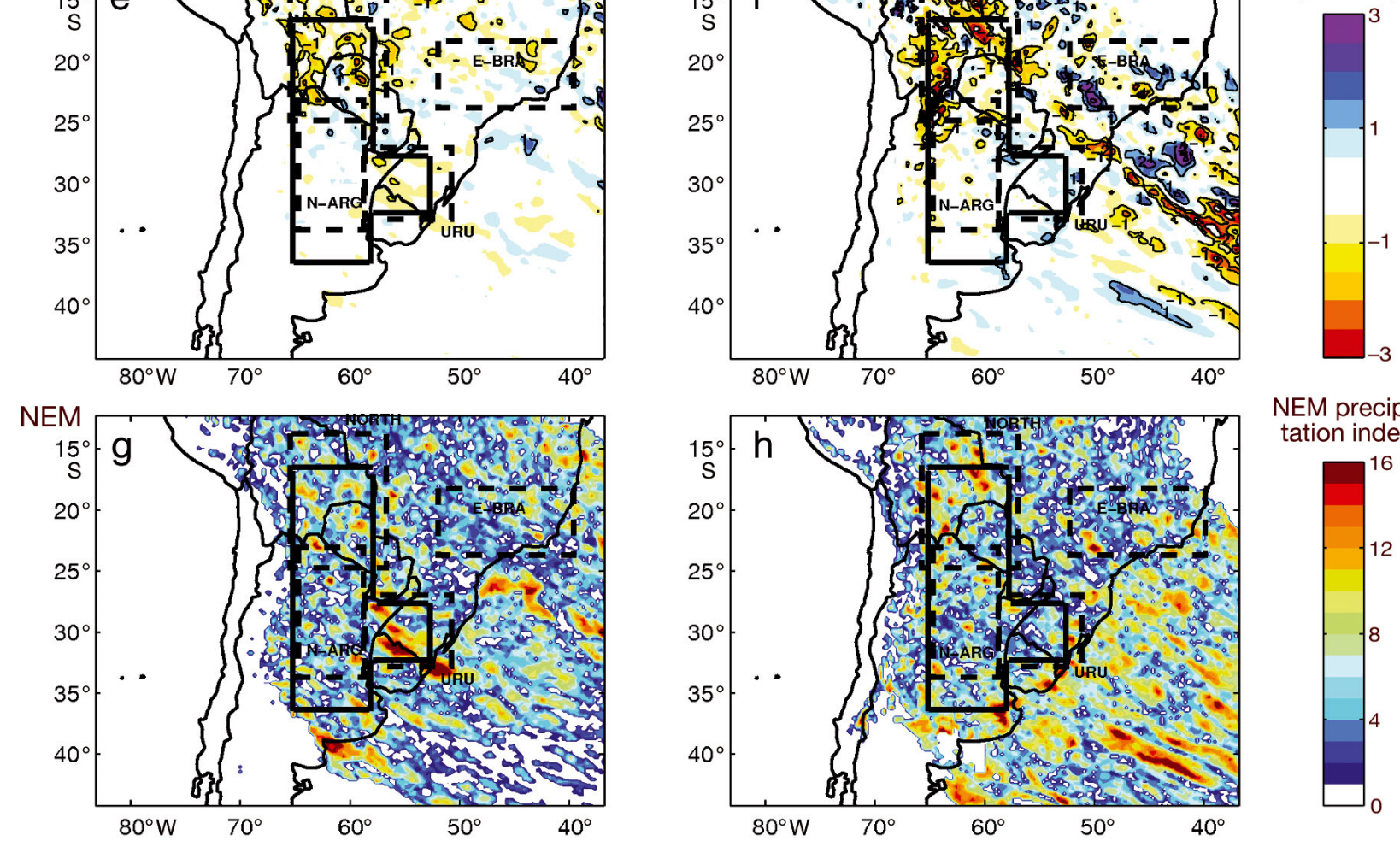

NEM precipitation index

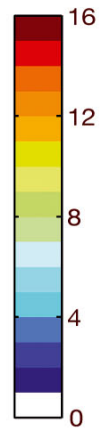

Fig. 8. Differences between CROP and FOREST ensembles in $T_{2 \mathrm{~m}}$ precipitation and NEM indices. See Fig. 4 for further details 


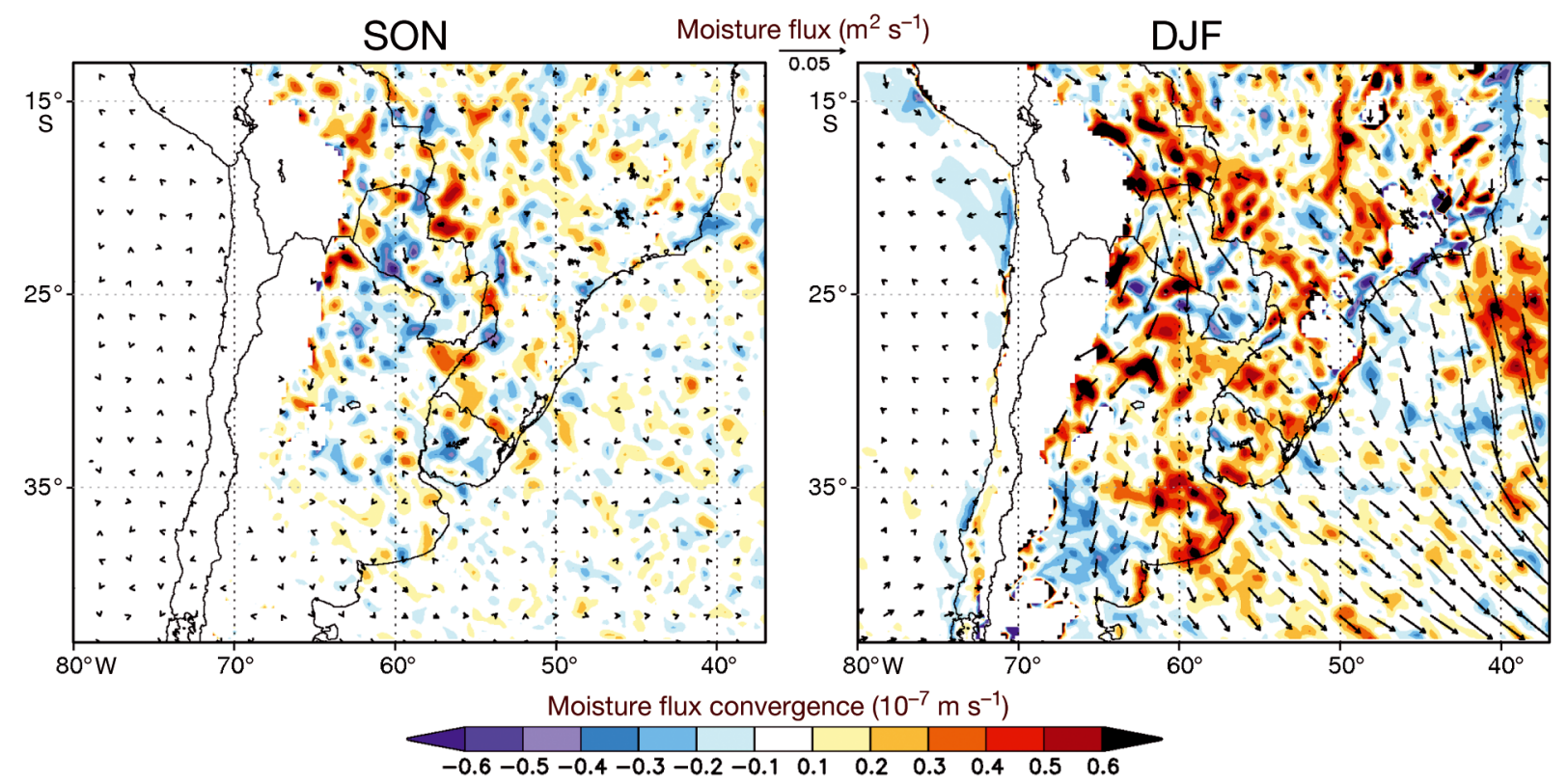

Fig. 9. Moisture flux (vectors) and moisture flux convergence (color) for the difference between CROP and FOREST experiments during seasons SON and DJF. See Fig. 7 for further details

by a reduction of the moisture flux convergence (Fig. 9 and Table 2) driven by a decrease in roughness length. Unlike the change in temperature, the changes in precipitation between CROP and FOREST have a similar spatial structure to the changes detected between BARE and FOREST scenarios, which may be due to a decrease in the roughness length. Over the E-BRA region, the increase of moisture flux convergence during DJF explains the increase in precipitation.

\subsubsection{CROP and CTRL scenarios}

In this section we discuss a more realistic scenario in which the actual land cover is replaced by crops over LPB and the Argentinean Pampas, in order to identify mechanisms that may trigger a response in the regional climate. When comparing the CROP and CTRL ensembles, one should keep in mind that changes in the physical properties of the surface are region-dependent. The CROP ensemble assumes that crops replace mostly savanna and patches of evergreen broadleaf forest over the NORTH region, patches of savanna, cropland/woodland mosaic and grasslands over N-ARG, and cropland/woodland mosaic and grasslands over URU. These land-use changes imply a weak reduction of albedo and an increase of emissivity over the NORTH region (the opposite behaviour compared with changing from forest to bare soils), a reduction of albedo and an increase of roughness length where crops replace grasslands and an increase of the roughness length where crops replace cropland/woodland mosaics (Table 1). Therefore, over the NORTH region there is a generalized change in albedo and emissivity, and over N-ARG and URU regions changes in surface properties are heterogeneous. The CROP scenario is similar to that described by Lee \& Berbery (2011), except for the extension of the area where crops replaced the actual vegetation cover.

Differences in temperature between CROP and CTRL ensembles (Fig. 10) show a weak cooling over NORTH and N-ARG regions during SON. Though the magnitude of the response is close to the magnitude of the internal variability, the NEM index shows that most of the pairs of the CTRL and CROP ensembles capture this behaviour. During DJF the temperature response is intensified over the NORTH region and the signal is significant in terms of both the internal variability and the NEM index. The response in precipitation due to a shift from actual land cover to crops (Fig. 10) is noisy during the austral spring season; however, during austral summer it is possible to detect consistent wetter (drier) conditions over the NORTH (E-BRA) region. The magnitude of the response is close to the internal variability; however, most of the pairs of individual ensemble members from the CROP and CTRL ensembles detect the precipitation response.

The cooling and wetting in the CROP ensemble over the NORTH region can be explained in terms of the changes in the energy budget when crops re- 

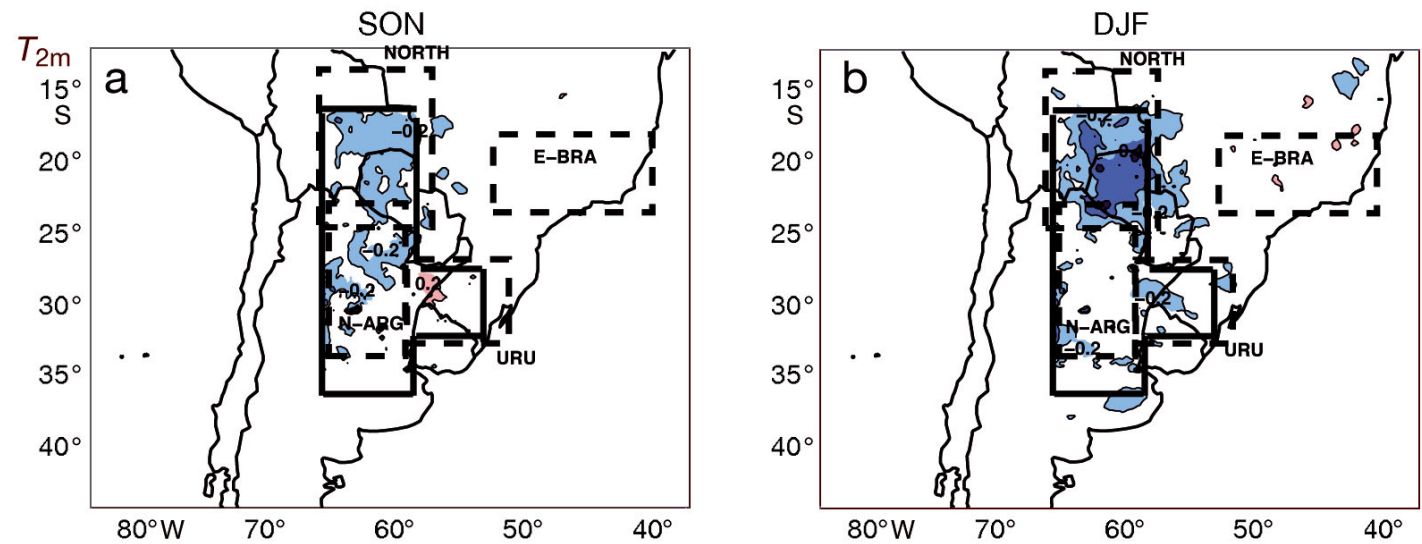

Temperature $\left({ }^{\circ} \mathrm{C}\right)$
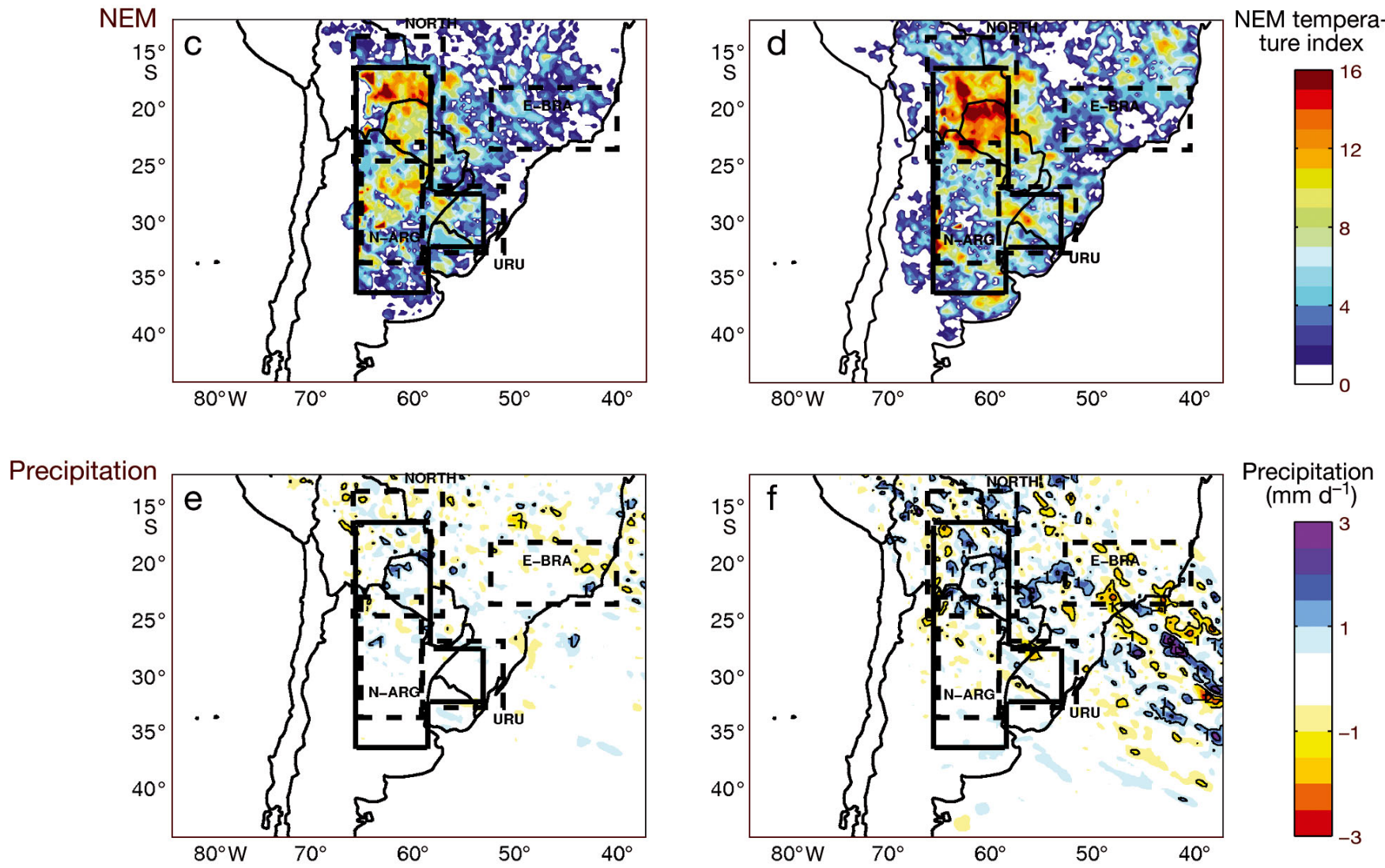

Precipitation $\left(\mathrm{mm} \mathrm{d}^{-1}\right)$
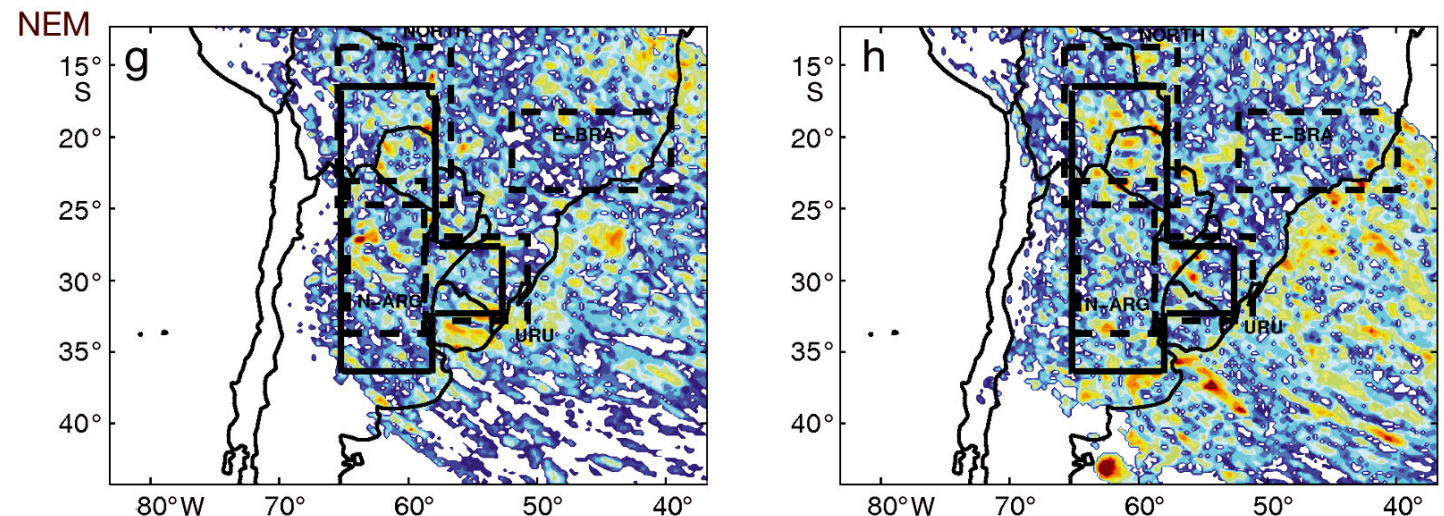

NEM precipitation index

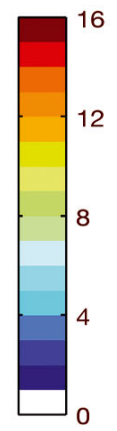

Fig. 10. Differences between CROP and CTRL ensembles in $T_{2 \mathrm{~m}}\left({ }^{\circ} \mathrm{C}\right)$, precipitation $\left(\mathrm{mm} \mathrm{d}^{-1}\right)$ and NEM indices. Refer to Fig. 4 

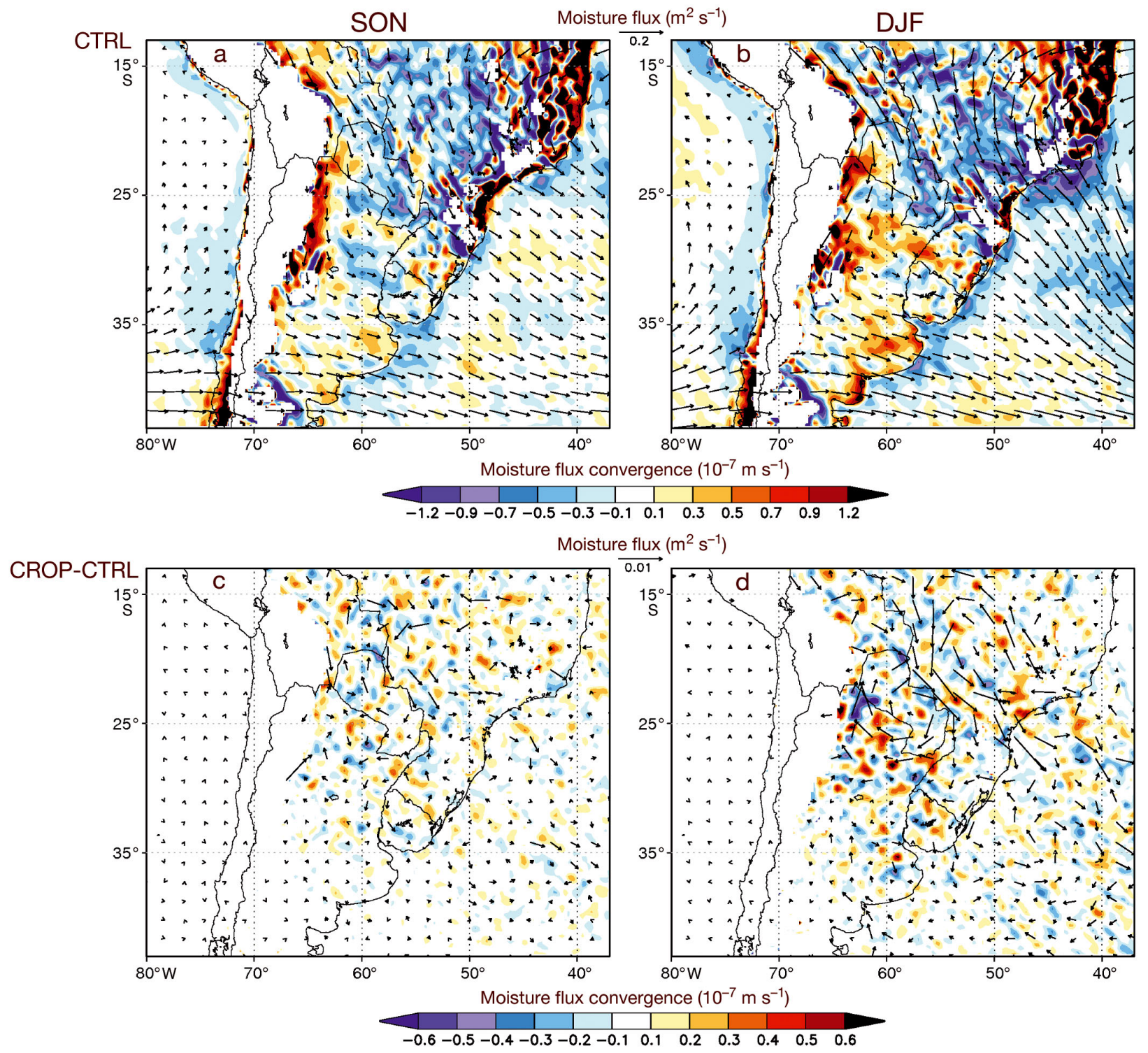

Fig. 11. Moisture flux (vectors in $\mathrm{m}^{2} \mathrm{~s}^{-1}$ ) and moisture flux convergence (shaded in $\left.10^{-7} \mathrm{~m} \mathrm{~s}{ }^{1}\right)$ for $(\mathrm{a}, \mathrm{b}) \mathrm{CTRL}$ and $(\mathrm{c}, \mathrm{d})$ the difference between CROP and CTRL experiments during seasons SON and DJF. Refer to Fig. 7

place the actual vegetation cover. The changes in emissivity and albedo over NORTH yield a decrease in the net radiation budget during both SON and DJF (Fig. 5e,f) due to the dominant effect of emissivity on the net long-wave radiation budget. The latent heat flux increases; consequently the evaporation from the surface increases and the sensible heat flux decreases. These changes are stronger during DJF compared with SON (Fig. 6e,f). The convergence of moisture flux remains similar for both CROP and CTRL ensembles (Fig. 11 and Table 2); consequently, it does not contribute much to the precipitation change over the NORTH region. Note that reductions of the roughness length occur only over grid points where evergreen broadleaf is replaced by crops (Table 1). Over N-ARG a slight decrease of the net radiation budget and an increase (decrease) of the latent (sensible) heat flux during SON may explain the cooling over that region. For those regions where grassland and cropland/woodland mosaic were replaced by crops (N-ARG and URU), the responses of temperature and precipitation are very weak since changes in surface parameters are subtle and heterogeneous within the region; consequently, when evaluating area averages, small differences may be compensated within the region. The spatial pattern of the change in latent and sensible heat flux for DJF (Fig. 12) reinforces this behaviour. No 

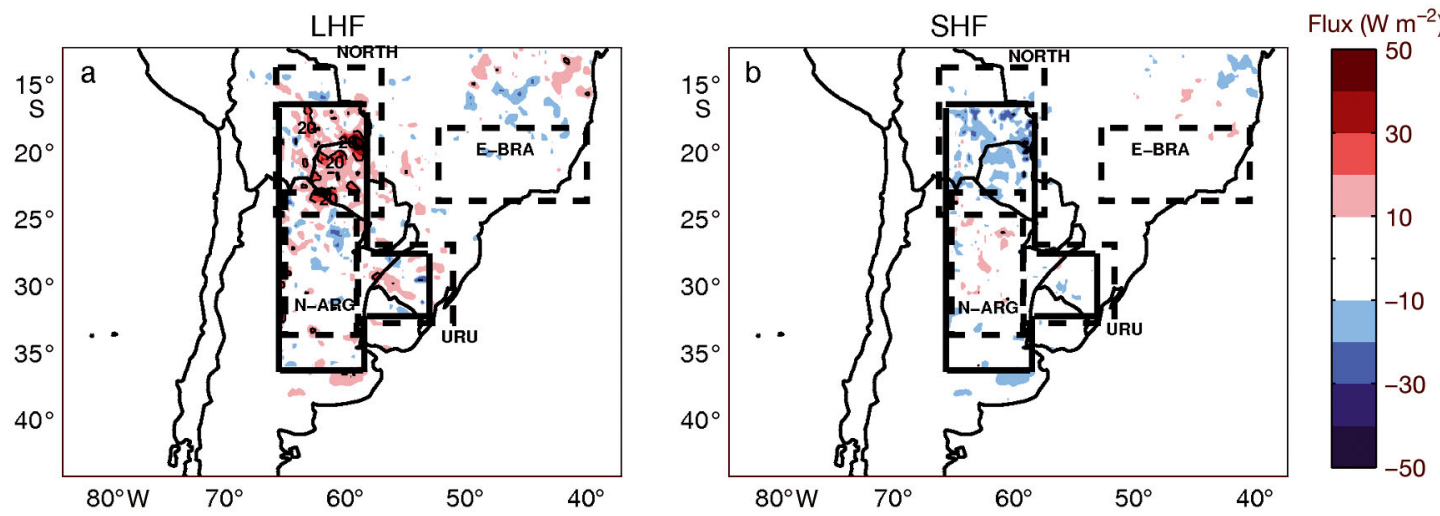

Fig. 12. Differences between CROP and CTRL ensembles for (a) latent (LHF) and (b) sensible (SHF) heat fluxes (W $\mathrm{m}^{-2}$ ) during Dec-Feb (DJF). For region details see Fig. 4

changes are apparent over E-BRA for the energy budget components; however, the decrease of the moisture flux convergence during DJF may explain the drying response over that area.

The results shown in Fig. 10 agree with those presented by Lee \& Berbery (2011) who also found a cooling driven by a shift from savanna to crops during the spring season over the northern part of LPB. Moreover, their pattern of precipitation change also agrees with our results, though the land-use scenario in their study is not the same as the one evaluated in this work.

\section{SUMMARY AND CONCLUSIONS}

This study examines the effects of LULCC on regional climate over LPB and the Argentinean Pampas through a series of sensitivity experiments performed with the MM5 RCM, in which the actual vegetation cover was replaced by forest, bare soils and crops, respectively. The experiments were performed for 2 particular seasons, SON and DJF 1996-1997, characterized by neutral conditions (non-ENSO) that allowed us to isolate the physical signal that arises from local forcing related to LULCC.

The sensitivity experiments suggested that the biophysical regulation of climate by ecosystems strongly influences temperature and precipitation through changes in the energy and water budgets. An idealized desertification scenario, where forest was replaced by bare soils, showed a significant warming and drying due to an increase in the net radiation budget and a reduction in latent heat flux. Changes in albedo and emissivity due to LULCC arise as the most sensitive parameters controlling the net radiation budget at the surface. Changes in surface roughness and root length contribute to changes in the surface fluxes. The largest precipitation response is found over Bolivia and western Paraguay, where the reduction in precipitation is due to both local (latent heat flux) and non-local (moisture flux convergence) effects.

The replacement of forests by crops resulted in a decrease in the net radiation budget at the surface, together with a decrease in the latent and sensible heat fluxes, driving a significant cooling over central and eastern Argentina and drying over Bolivia and western Paraguay during the austral spring and summer periods. Replacing forests with crops or bare soil implies an increase in albedo, a decrease in surface roughness and root depth and an increase or decrease in emissivity, respectively. These changes trigger an opposite response in temperature, mainly over central Argentina, but a similar response in precipitation. Moreover, the larger the differences in the physical properties of the land surface, the larger the response.

The analysis of these idealized and homogeneous scenarios of LULCC allow us to understand to what extent surface properties act as regulators of regional climate conditions. However, even though the changes in land surface imposed were uniformly distributed, the climate response was not. Moreover, the regional response exceeds the area where the landuse was changed, indicating that non-local mechanisms can be important external to the area affected by changes in land cover.

The effects due to a shift from actual land cover to crops resulted in a cooling and wetting mainly over northern Argentina, Paraguay and part of Bolivia (NORTH region). The cooling is the result of a decrease in the net radiation budget and the sensible heat flux from the surface; the wetting is due to the increase in latent heat flux, in agreement with Lee \& Berbery (2011), who found similar results over the 
northern part of LPB. Moreover, the changes in surface properties over this area is opposite to that imposed when forests were replaced by bare soils; accordingly, the response in precipitation and temperature is opposite too. Though the land use was changed over a broad region extending to $35^{\circ} \mathrm{S}$, no significant responses were found out of the NORTH region.

Overall, for all the scenarios analyzed, the responses were found to be stronger during the austral summer season compared with the austral spring season. This may be due to the surface fluxes, which are strongly affected by land-cover properties, becoming more relevant during summer. Moreover, the region located over western Paraguay, Bolivia and northern Argentina seems to depict the largest response in terms of temperature and precipitation due to land-use changes. This result suggests that other regions within the LPB and the Argentinean Pampas are not as sensitive to local forcings. Further analysis should include simulations spanning several years, in order improve the robustness of the results.

Acknowledgements. The authors wish to acknowledge 4 anonymous reviewers for insightful comments and suggestions that led to improvements in the manuscript. Funding was received from the European Community's Seventh Framework Programme (FP7/2007-2013) under Grant Agreement $N^{\circ} 212492$ (CLARIS LPB: a Europe-South America Network for Climate Change Assessment and Impact Studies in La Plata Basin). This work has also been supported by FONCYT Grant PICT05 32194, UBACyT Grant X160, Conicet Grant PIP 112-200801-00195.

\section{LITERATURE CITED}

Achard F, Eva HD, Stibig HJ, Mayaux P, Gallego J, Richards T, Malingreau JP (2002) Determination of deforestation rates of the world's humid tropical forests. Science 297: 999-1002

Alexandru A, de Elia R, Laprise R (2007) Interanual variability in regional climate downscaling at the seasonal scale. Mon Weather Rev 135:3221-3238

Baldi G, Paruelo JM (2008) Land use and land cover dynamics in South American temperate grasslands. Ecol Soc 13(2):6 [online], available at: www.ecologyandsociety. org/vol13/iss2/art6/

Barreiro M, Díaz N (2011) Land-atmosphere coupling in El Niño influence over South America. Atmos Sci Lett 12: 351-355

Beltrán-Przekurat A, Pielke RA, Eastman JL, Coughenour MB (2011) Modelling the effects of land-use/land-cover changes on the near surface atmosphere in southern South America. Int J Climatol 32:1206-1225

Betts AK, Ball JH, Beljaars ACM, Miller MJ, Viterbo PA (1996) The land surface-atmosphere interaction: a review based on observational and global modeling perspectives. J Geophys Res 101(D3):7209-7226

Blatter P, Ruiz J, Pulido M (2010) The impact of deforestation of the Gran Chaco in the precipitation of Gran Chaco and surrounding region. Eos Trans AGU 91(26), Meet Am Suppl, Abstract A33C-01

Bonan G (1999) Frost followed the plow: impacts of deforestation on the climate of the United States. Ecol Appl 9: 1305-1315

Chen F, Dudhia J (2001) Coupling and advanced land surface hydrology model with the Penn State-NCAR MM5 modeling system. I. Model implementation and sensitivity. Mon Weather Rev 129:569-585

Costa M, Pires G (2010) Effects of Amazon and Central Brazil deforestation scenarios of the duration of the dry season in the arc of deforestation. Int J Climatol 30: 1970-1979

FAO (2006) Tendencias y perspectivas del sector forestal en América Latina y el Caribe. Estudio FAO Montes 148, Roma. ftp://ftp.fao.org/docrep/fao/009/a0470s/a0470s00. pdf

Fearnside PM (2001) Soybean cultivation as a threat to the environment in Brazil. Environ Conserv 28:23-38

Garand L (1983) Some improvements and complements to the infrared emissivity algorithm including a parameterization of the absorption in the continuum region. J Atmos Sci 40:230-244

Grell GA (1993) Prognostic evaluation of assumptions used by cumulus parameterizations. Mon Weather Rev 121: 764-787

> Hong S, Pan H (1996) Non-local boundary layer vertical diffusion in a medium-range forecast model. Mon Weather Rev 124:2322-2339

Hsie EY, Anthes RA, Keyser D (1984) Numerical simulation of frontogenesis in a moist atmosphere. J Atmos Sci 41: 2581-2594

Kaimowitz D, Smith J (2001) Soybean technology and the loss of natural vegetation in Brazil and Bolivia. In: Angelsen A, Kaimowitz D (eds) Agricultural technologies and tropical deforestation. CAB International, Wallingford, p 195-211

Lee S, Berbery H (2011) Land cover change effects on the climate of the La Plata Basin. J Hydrometeor 13:84-102

Magrin G, Gay García C, Cruz Choque D, Giménez JC and others (2007) Latin America. Climate change 2007: impacts, adaptation and vulnerability. In: Parry ML, Canziani OF, Palutikof JP, van der Linden PJ, Hanson CE (eds.) Contribution of Working Group II to the Fourth Assessment Report of the Intergovernmental Panel on Climate Change. Cambridge University Press, Cambridge, p 581-615

Menéndez CG, de Castro M, Boulanger JP, D'Onofrio A and others (2010) Downscaling extreme month-long anomalies in southern South America. Clim Change 98:379-403

Nuñez M, Ciapessoni H, Rolla A, Kalnay E, Cai M (2008) Impact of land use and precipitation changes on surface temperature trends in Argentina. J Geophys Res 113: D06111, doi:10.1029/2007JD008638

> Oleson K, Bonan G, Levis S, Vertenstein M (2004) Effects of land use change on North American climate: impact of surface datasets and model biogeophysics. Clim Dyn 23: $117-132$

Pielke R, Pitman A, Niyogi D, Mahmood R and others (2011) Land use/land cover changes and climate: modeling analysis and observational evidence. WIREs Clim Change 2: $828-850$

Saulo C, Ferreira L, Nogués-Paegle J, Seluchi M, Ruiz J (2010) Land-atmosphere interactions during a north- 
western Argentina low event. Mon Weather Rev 138: 2481-2498

Simmons AS, Uppala DD, Kobayashi S (2007) ERA-interim: new ECMWF reanalysis products from 1989 onwards. ECMWF Newsl 110:29-35

Solman S, Pessacg N (2012a) Regional climate simulations over South America: sensitivity to model physics and to the treatment of lateral boundary conditions using the MM5 model. Clim Dyn 38:281-300

Solman S, Pessacg N (2012b) Evaluating uncertainties in regional climate simulations over South America at the seasonal scale. Clim Dyn 39:59-76

Solman S, Núñez M, Cabré MF (2007) Regional climate change experiments over southern South America. I. Present climate. Clim Dyn 30:533-552

Stephens GL (1978) Radiation profiles in extended water clouds. II. Parameterization schemes. J Atmos Sci 35: 2123-2132

Strengers BJ, Müller C, Schaeffer M, Haarsma RJ and others

Editorial responsibility: Filippo Giorgi,

Trieste, Italy
(2010) Assessing 20th century climate-vegetation feedbacks of land-use change and natural vegetation dynamics in a fully coupled vegetation-climate model. Int $\mathrm{J}$ Climatol 30:2055-2065

> Viglizzo EF, Frank FC (2006) Ecological interactions, feedbacks, thresholds and collapses in the Argentine Pampas in response to climate and farming during the last century. Quat Int 158:122-126

> Viglizzo EF, Roberto ZE, Lértora F, López Gay E, Bernardos $\mathrm{J}$ (1997) Climate and land-use change in field-crop ecosystems of Argentina. Agric Ecosyst Environ 66:61-70

> Weaver CP, Avissar R (2001) Atmospheric disturbances caused by human modifications of the landcape. Bull Am Meteorol Soc 82:269-282

West PC, Narisma GT, Barford CC, Kucharik CJ, Foley JA (2011) An alternative approach for quantifying climate regulation by ecosystems. Front Ecol Environ 9:126-133 Zalba SM, Villamil CB (2002) 2002: woody plant invasion in relictual grasslands. Biol Invasions 4:55-72

Submitted: November 3, 2011; Accepted: June 12, 2012 Proofs received from author(s): October 24, 2012 